\title{
New Multiphase Hybrid Boost Converter with Wide Conversion Ratio for PV System
}

\author{
Ioana-Monica Pop-Calimanu' ${ }^{1}$ and Folker Renken ${ }^{2}$ \\ ${ }^{1}$ Applied Electronics Department, "Politehnica" University of Timisoara, 300223 Timisoara, Romania \\ ${ }^{2}$ Power Electronics/Department of Engineering, "Jade University," University of Applied Sciences, \\ 26389 Wilhelmshaven, Germany
}

Correspondence should be addressed to Ioana-Monica Pop-Calimanu; ioanamonica.pop@gmail.com

Received 1 December 2013; Accepted 2 March 2014; Published 30 April 2014

Academic Editor: Ismail H. Altas

Copyright (C) 2014 I.-M. Pop-Calimanu and F. Renken. This is an open access article distributed under the Creative Commons Attribution License, which permits unrestricted use, distribution, and reproduction in any medium, provided the original work is properly cited.

\begin{abstract}
A new multiphase hybrid boost converter, with wide conversion ratio as a solution for photovoltaic energy system, is presented in this paper. To ensure that all the phases of the converter operate at the same switching frequency we use interleaving topology. The proposed converter can be used as an interface between the PV system and the DC load/inverter. This multiphase converter has the advantage of reduced value and physical size of the input and output capacitor as well as the effort for the inductors. To validate the operation of the converter we provide the analyses and the simulation results of the converter.
\end{abstract}

\section{Introduction}

Photovoltaic (PV) energy has attracted interest as an energy source capable of solving the problems of the energy crisis. Solar PV energy is becoming an increasingly important part of the renewable energy resources. It is considered one of the most promising energy resources due to its infinite power delivered directly for free, and many other advantages. These include reliability, availability, zero pollution or destruction of the land, reasonable installation and production cost, long life-span, and the capability of supporting microgrid systems and connecting to electrical grids [1-5]. One of the challenges in the case of grid connection applications or high voltage DC applications requirements is the low voltage of the PV module. For this reason, many PV modules should be either connected in series to meet these application requirements, or to use a step-up DC/DC converter. This type of converter is widely used in PV systems. Theoretically, a traditional step-up converter can achieve a high stepup voltage gain with an extremely high duty ratio near to $100 \%$ [6]. The step-up voltage gain in practice is limited due to the effect of power switches, rectifier diodes, the equivalent series resistance of inductors and capacitors, and the saturation effects of the inductors and capacitors [7]. Due to the fact that these traditional converters are not able to operate efficient with a high duty ratio near to $100 \%$, scientific literature presents many topologies [8-11] that provide a high step-up voltage gain without an extremely high duty ratio. A very good review of nonisolated high step-up DC/DC converters used in renewable energy applications is presented in $[12,13]$, where the advantages and disadvantages of these converters and the major challenges are summarized. In [14] the architecture of a high step-up converter, which contains seven parts including a PV module input circuit, a primaryside circuit, a secondary-side circuit, a passive regenerative snubber circuit, a filter circuit, a DC output circuit, and a feedback control mechanism, is presented. The authors from [14], for raising the voltage gain, are using a coupled inductor with a low-voltage rated switch. In [15] three types of step-up converters with high-efficiency by using PV system with reduced diode stresses sharing are proposed. Through the employ of coupled inductor and switched capacitor, the 


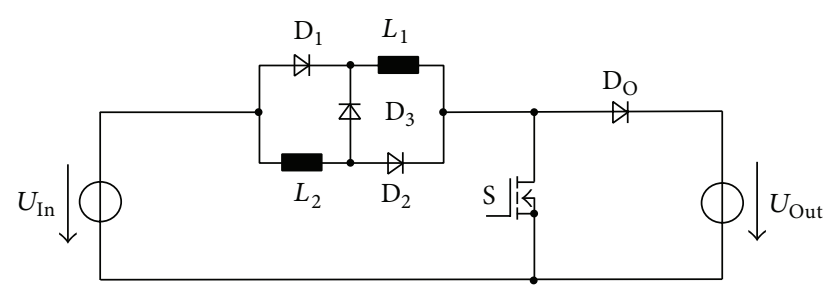

FIGURE 1: Single-phase hybrid boost DC/DC converter.

proposed converters attain high step-up conversion ratio without operating at extreme duty ratio. Very often in the literature is presented high step-up DC/DC converter that utilizes at least one coupled inductor. One of these structures is presented in [16] where the operating principle and steady state analyses are discussed in detail, and a prototype of the circuit is implemented. Another configuration of stepup converter with coupled inductor is presented in [17]. This converter achieves a high step-up voltage conversion ratio, without extreme duty ratios and the numerous turn's ratios of a coupled inductor. The leakage inductor energy of the coupled inductor is efficiently recycled to the load. Other high step-up DC/DC converters with coupled inductor are presented in [18-21].

In this paper is presented and analysed the structures of the step-up hybrid boost converter [7,22], or as named in some papers switched inductor boost type.

One of the main disadvantages of this circuit is that the effort for the input and output capacitor, in the case of a single-phase $\mathrm{DC} / \mathrm{DC}$ converter is very high. This is the same with the effort of the inductors. Based on the structure of the hybrid boost converter built in multiphase design, we present a method for reducing this disadvantage through a new multiphase hybrid boost converter.

\section{Single-Phase Hybrid Boost Converter}

Figure 1 shows the step-up hybrid boost converter which was introduced in [22]. The hybrid boost DC/DC converter consists of a classical boost converter in which is inserted an L-switching structure. The L-switching structure consists of two inductors and three diodes. We can simply say that the input inductor from a classical boost converter was replaced by the two inductors in the new hybrid converter. This type of converter provides high gain and high efficiency and is used for many applications such as solar cell energy conversion systems [7], fuel cell energy conversion systems, battery backup systems for uninterruptible power supplies, and high intensity discharge lamp ballast for automobile head lamps [23].

The gain of the hybrid boost converter is higher than the traditional boost converter by a factor of $(d+1)$. Figure 2 shows a comparison between the gain of the hybrid boost converter and the traditional boost converter.

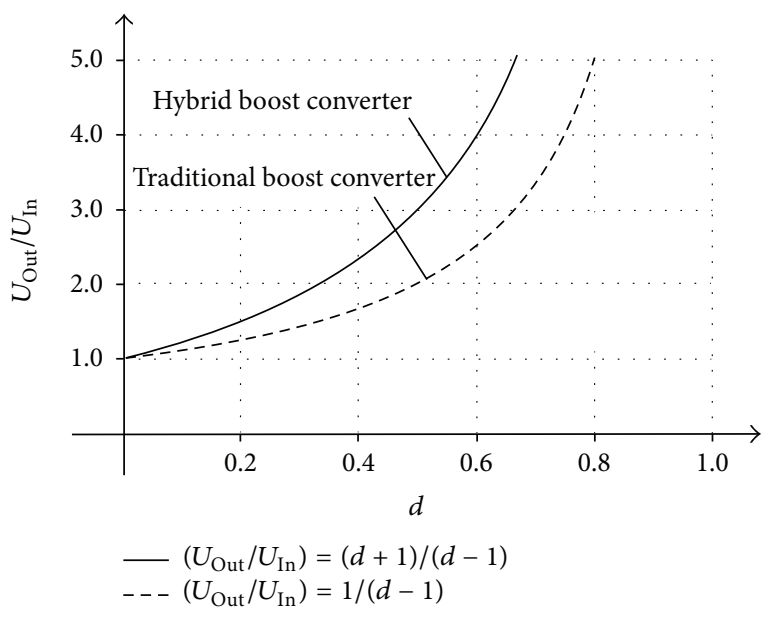

FIGURE 2: Conversion ratio of a hybrid boost and traditional boost DC/DC converter.

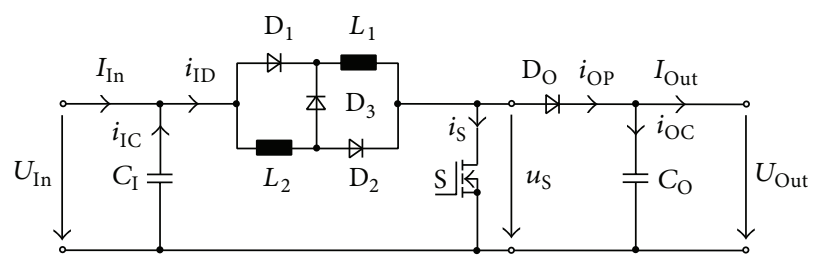

FIgURE 3: Single-phase hybrid boost DC/DC converter.
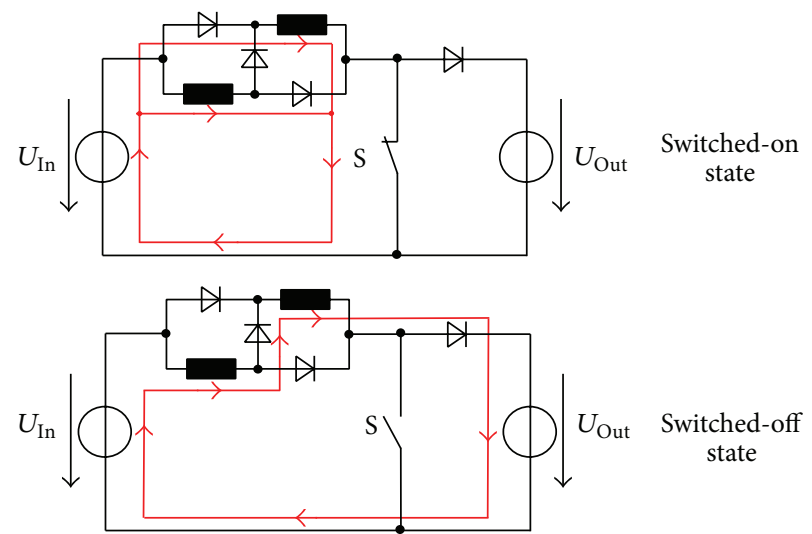

FIGURE 4: Current flow in switched-on and switched-off state of the hybrid boost DC/DC converter.

To ensure a better understanding, this section continues by presenting and discussing the power part of the hybrid converter, which is presented in Figure 3.

The power part consists of an input network with two inductors and three diodes, a step-up circuit with the power switch $\mathrm{S}$ and diode $\mathrm{D}_{\mathrm{O}}$, as well as a DC-link capacitor at the input and output side of the converter. Based only on the circuit structure, we can observe that the energy can be transferred only in one direction from input to output. 

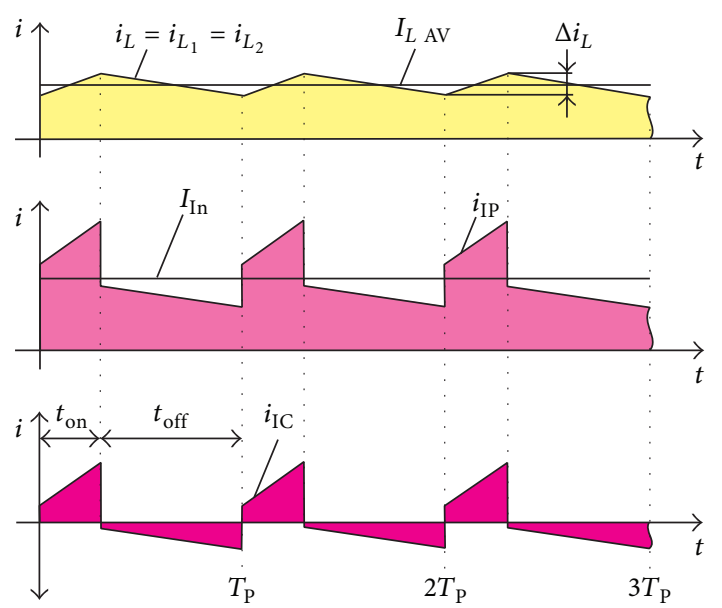

Figure 5: Current waveforms at the input of a single-phase hybrid boost DC/DC converter $(d=0.3)$.

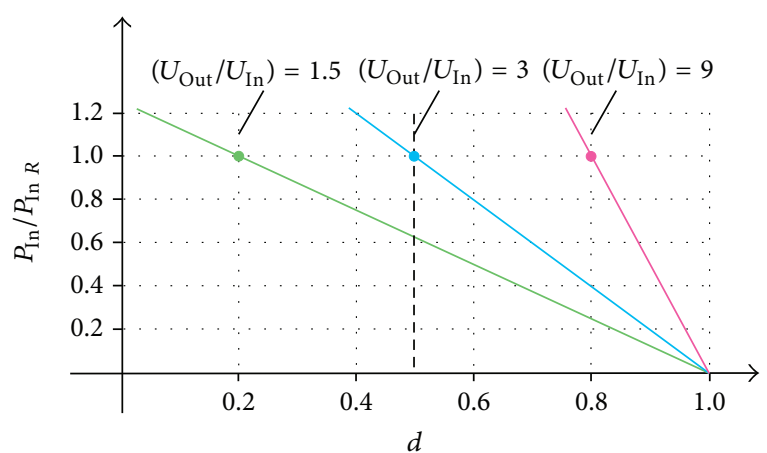

FIGURE 6: Maximum power transfer in case of fixed output voltage.

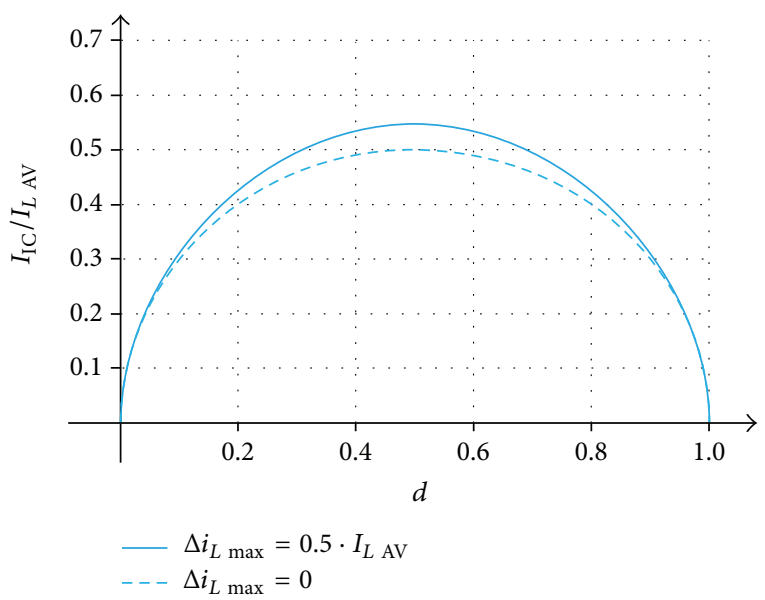

FIGURE 7: RMS current in the input capacitors of a single-phase hybrid boost DC/DC converter.
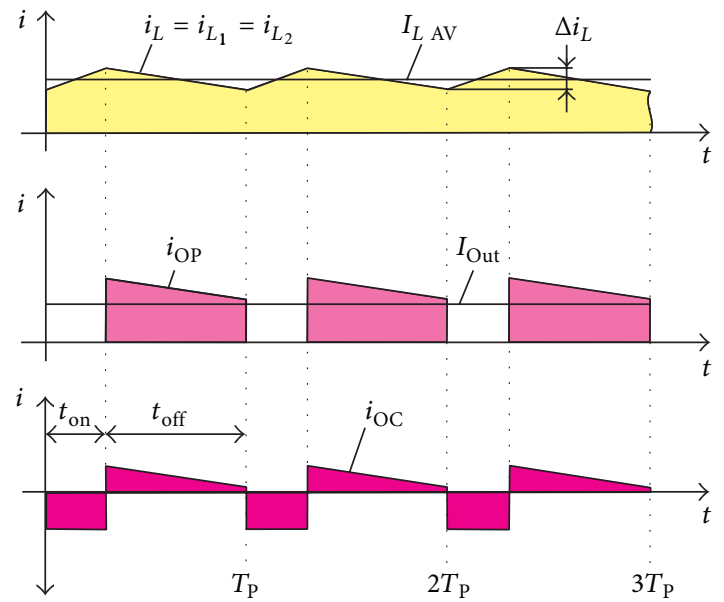

FIGURE 8: Current waveforms at the output of a single-phase hybrid boost DC/DC converter $(d=0.3)$.

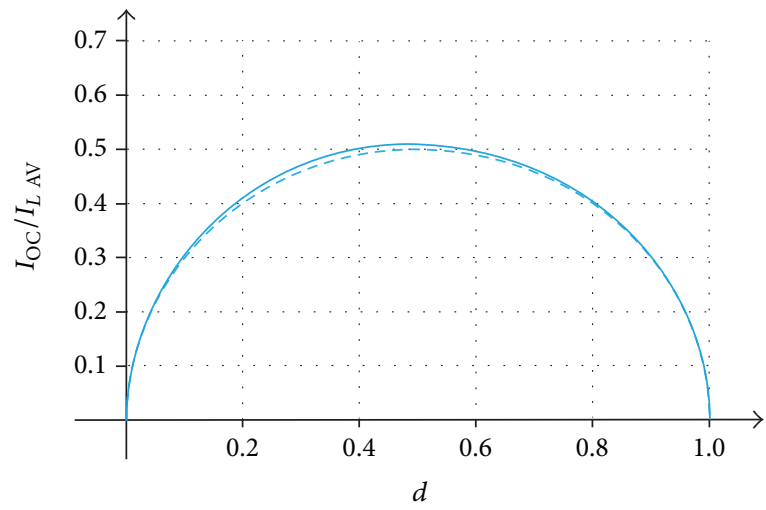

$-\Delta i_{L \max }=0.5 \cdot I_{L \mathrm{AV}}$

- - $\Delta i_{L \max }=0$

FIGURE 9: RMS current in the output capacitors of a single-phase hybrid boost DC/DC converter.

For operation of the converter we use a pulse control method. Figure 4 shows the current flow in the circuit in the switched-on and the switched-off state.

In the switched-on state the inductors are connected in parallel and the current of both inductors flows in the input phase and in the switch element. For this reason during the switched-on state the current in the output phase $i_{\mathrm{OP}}$ is zero (Figure 8). In the switched-off state the inductance current flows in series through the inductors and the output diode. In this moment the inductors are connected in series, while the input phase current $i_{\mathrm{IP}}$ and output phase current $i_{\mathrm{OP}}$ are the same as the inductor current. The expectation being that only the average value of the input phase current would flow in the converter input current, $I_{\text {In }}$, while the AC-current component 
would flow in to the capacitor $C_{\mathrm{I}}$ and the average value of the output phase current would flow in the converter output $I_{\text {Out }}$.

For calculations, we assumed that all elements of the converter would work without losses, the voltage and currents at the input and output were ideally DC-values, and the converter would be controlled with pulse width modulation [24]. With these requirements in the converter switching states, the voltage at the inductors can be determined by applying the voltage-second balance on the inductor as follows:

$$
\begin{gathered}
t_{\text {on }}: \quad u_{L}=U_{\text {In }}, \\
t_{\text {off }}: \quad u_{L}=-\frac{U_{\text {Out }}-U_{\text {In }}}{2},
\end{gathered}
$$

where $u_{L}$ is the inductor voltage, $U_{\text {In }}$ is the input voltage, and $U_{\text {Out }}$ is the output voltage.

As we can see from the above formulas, the voltage at the inductors is positive in the switched-on state and negative in the switched-off state. In circuit operation the positive and negative voltage-time-area at the inductors must always be the same. With this condition the conversion ratio of the hybrid boost DC/DC converter can be calculated. Consider

$$
U_{\text {Out }}=\frac{1+d}{1-d} \cdot U_{\text {In }} \quad \text { with } d=\frac{t_{\text {on }}}{T_{\mathrm{P}}}, 1-d=\frac{t_{\text {off }}}{T_{\mathrm{P}}} .
$$

2.1. DC/DC Converter Input Circuit. In Figure 5 the current waveforms at the input of the hybrid boost converter is presented. The first waveform shows the currents in both inductors, and we can see that they are the same. The inductor current rises in switched-on state and fall in switched-off state, so that a triangular shape current is generated. The middle waveform presents the input phase current $i_{\mathrm{IP}}$, and the lower waveform presents the input capacitor current $i_{\mathrm{IC}}$.

The average current $I_{L A V}$ depends on the duty cycle $d$. Consider

$$
I_{L \mathrm{AV}}=\frac{I_{\mathrm{In}}}{1+d} .
$$

In order to calculate the required inductance and capacitance in the circuit we needed to fix conditions for the circuit operation. We first needed to know the rated output voltage, as well as the minimal input voltage at rated power which should be transferred. With these conditions the conversion ratio of the circuit for rated input power $P_{\operatorname{In} R}$ transfer is fixed.

In this operation point the DC-input current and the average current $I_{L \mathrm{AV}}$ in the inductors can be calculated. It is assumed that this average current $I_{L \mathrm{AV}}$ is the maximum DC-value in the inductances. Figure 6 shows the possible power transfer dependent on the duty cycle for three different converter designs. The inductivity must be calculated for the maximum inductor voltage-time-area within the pulse periods and the maximum acceptable current variation during this time. In the switched-on state $t_{\text {on }}$, the input voltage $U_{\text {In }}$ is connected at the inductors. The voltage $U_{\text {In }}$ is described in formula (5) as a function of the output voltage and the duty cycle. Consider

$$
\begin{gathered}
L_{1}=L_{2}=\frac{U_{\text {In }} \cdot t_{\mathrm{on}}}{\Delta i_{L}}, \\
L_{1}=L_{2}=\frac{U_{\mathrm{Out}} \cdot T_{\mathrm{P}}}{\Delta i_{L}} \cdot \frac{d \cdot(1-d)}{1+d} .
\end{gathered}
$$

Considering the full duty cycle range, the voltage-timearea within the pulse periods reaches its maximum for a duty cycle of approximately $41 \%$. For this duty cycle in general the converter inductance is specified. The maximum acceptable current variation $\Delta i_{L \text { max }}$ is chosen normally between $10 \%$ and $30 \%$ of the rated average inductance current $I_{L A V R}$. These inductances can be realized as individual or mutual coupled inductances.

$$
\begin{aligned}
& L_{1}=L_{2}=\frac{U_{\mathrm{Out}} \cdot T_{\mathrm{P}}}{\Delta i_{L \max }} \cdot(3-2 \cdot \sqrt{2}) \\
& \text { with } \Delta i_{L \max }=(0.1-0.3) \cdot I_{L \mathrm{AV} R} .
\end{aligned}
$$

We continue with the calculation of the capacity of the input side. We begin with the worst case scenario which could happen when the converter input current is an ideally average value and the overall $\mathrm{AC}$-current of the input phase flows in the capacitor (see Figure 4). This AC-current in the capacitor produces an AC-voltage at the input that is overlaid with the DC-input voltage. For this reason the maximum acceptable voltage variation at the capacitor must be chosen during the capacity dimension. Consider

$$
\begin{aligned}
& C_{\mathrm{I}}=\frac{i_{\mathrm{C}} \cdot t_{\mathrm{on}}}{\Delta u_{\mathrm{C}}}, \\
& C_{\mathrm{I}}=\frac{I_{L A V} \cdot T_{\mathrm{P}}}{\Delta u_{\text {In } \max }} \cdot d \cdot(1-d) .
\end{aligned}
$$

The current-time-area depends on the duty cycle having its maximum at $50 \%$ and at the rated inductance current $I_{L A V}$. In practice, the acceptable static voltage variation at the converter input is chosen smaller than $1 \%$ of the rated input voltage $U_{\operatorname{In} R}$.

$$
C_{\mathrm{I}}=\frac{I_{L A V R} \cdot T_{\mathrm{P}}}{4 \cdot \Delta u_{\text {In } \max }} \quad \text { with } \Delta u_{\text {In } \max } \leq 0.01 \cdot U_{\text {In } R} .
$$

In the input of the DC/DC converters, electrolytic capacitors are often used [25]. The main design criteria for these capacitors are the RMS current loads. The RMS current in the input capacitor is calculated as a function of the duty cycle for an average inductance current $I_{L A V}$ and a maximum current variation $\Delta i_{L \max }$. Consider

$$
\begin{aligned}
& I_{\mathrm{IC}} \\
& =I_{L \mathrm{AV}} \\
& \quad \cdot \sqrt{d \cdot(1-d)+\left(\frac{\Delta i_{L \max }}{I_{L \mathrm{AV}}}\right)^{2} \cdot \frac{d^{2} \cdot(1-d)^{2} \cdot(1+3 \cdot d)}{12 \cdot(1+d)^{2} \cdot(3-2 \cdot \sqrt{2})}} .
\end{aligned}
$$


The result can be split into two. One is dependent on the average current $I_{L \mathrm{AV}}$ and the other is dependent on the triangle current variation in the inductances. In Figure 7, the current in the RMS capacitor is shown. The maximum value of the capacitor current is higher than the half average inductance current $I_{L \mathrm{AV}}$. The current variation has, however, only a small influence on the total RMS current in the capacitor.

2.2. DC/DC Converter Output Circuit. Figure 8 shows the current and voltage waveforms at the output of the hybrid boost DC/DC converter.

The first waveform in Figure 8 shows the current in both inductors. The middle waveform presents the output phase current $i_{\mathrm{OP}}$. The lower waveform shows the AC-current in the output capacitor. This current can be calculated by subtraction of output phase current $i_{\mathrm{OP}}$ and output current $I_{\text {Out }}$.

We continue with the calculation for the capacity of the output side. We begin with the worst case scenario which would happen when the converter output current is an ideally average value and the overall $\mathrm{AC}$ component of the output phase current flows in the capacitor (see Figure 8). This ACcurrent in the capacitor produces an AC-voltage at the output that is overlaid with the DC-output voltage. For this reason the maximum acceptable voltage variation at the capacitor must be chosen during the capacity dimension. The currenttime-area in the capacitor within the pulse periods can be described as a function of the output current and the duty cycle. Consider

$$
\begin{gathered}
C_{\mathrm{O}}=\frac{I_{\text {Out }} \cdot T_{\mathrm{P}}}{\Delta u_{\text {Out max }}} \cdot d, \\
C_{\mathrm{O}}=\frac{I_{L A V} \cdot T_{\mathrm{P}}}{\Delta u_{\text {Out max }}} \cdot d \cdot(1-d) .
\end{gathered}
$$

The current-time-area depends on the duty cycle with its maximum at $50 \%$ and at rated inductance current $I_{L \mathrm{AV}}$. In practice, the acceptable static voltage variation is chosen smaller than $1 \%$ of the nominal output voltage $U_{\text {Out }}$. Consider

$$
C_{\mathrm{O}}=\frac{I_{L A V R} \cdot T_{\mathrm{P}}}{4 \cdot \Delta u_{\text {Out } \max }} \quad \text { with } \Delta u_{\text {Out } \max } \leq 0.01 \cdot U_{\text {Out } R} \text {. }
$$

Also on the output side of the hybrid boost converters, electrolytic capacitors are often used. For design of the capacitors, the RMS current in the output must be calculated. In the next formula the RMS current is determined as a function of the duty cycle for an average inductance current $I_{L A V}$ and a maximum inductance current variation $\Delta i_{L \max }$. Consider

$$
\begin{aligned}
& I_{\mathrm{OC}} \\
& =I_{L \mathrm{AV}} \\
& \quad \sqrt{d \cdot(1-d)+\left(\frac{\Delta i_{L \max }}{I_{L \mathrm{AV}}}\right)^{2} \cdot \frac{d^{2} \cdot(1-d)^{3}}{12 \cdot(1+d)^{2} \cdot(3-2 \cdot \sqrt{2})}} .
\end{aligned}
$$

The result can also be split into two: one is dependent on the average inductor current $I_{L \mathrm{AV}}$, and the other is dependent on the triangle current variation in the inductances. In Figure 9, the current in the RMS capacitor is shown. The maximum value is more than the half average inductance current $I_{L A V}$. The current variation also has only a small influence on the total RMS current in the capacitor.

The effort for the input and output capacitor in the case of a single-phase DC/DC converter is very high. In the next section a method for reducing the capacitor currents is presented. With this method, the effort for the inductors can also be reduced.

\section{Multiphase DC/DC Converter}

Several solutions and their control were presented in the literature for interconnection of the converters [26-32]. Multiphase configuration is one of them [33-35]. Although the physical connection of the multiphase looks exactly the same like parallel connection, the main difference between them is the method of how they time/control their main switches. The parallel configuration is operated by having the switching signals for main switches coincide with each other (e.g., when switch from first power converter turns on, so does the switch from the second power converter and vice versa). The main advantage of parallel configuration is that the control circuit must only provide a single switching signal.

In multiphase converter each switch operates at a different time with a phase shift between the switch gate drivers [36] but with common frequency. The result of the phase delay allows multiphase configurations to exhibit higher overall efficiency due to ripple cancelation, smaller output filter requirements, and smaller output voltage ripple [37-40]. The output voltage ripple is reduced because the output frequency is increased by the number of phase times of the individual switch frequency. Higher output frequency makes the output ripple easier to filter which allows smaller components and further increase in efficiency [36]. In [41] is presented another two-phase boost converter topology, which due to the fact that the multiphase configuration, at the output the circuit, will have just a single capacitor and the output voltage will have ripple component twice the operating switching frequency of each individual boost converter. The frequency multiplication effect also occurs at the input side of the converter and will reduce the input filters and will improve the quality of the input current [41].

The hybrid boost DC/DC converter presented in this paper can also be built in multiphase design. Therefore the different phases are connected at a common input and output capacitor. The total current is subdivided in the different phases. By interleaving switching topology the AC-currents in the input $C_{\mathrm{I}}$ and output capacitor $C_{\mathrm{O}}$ can be reduced clearly. In addition the frequency of the capacitor currents is increased. With suitable circuit design the effort of the inductances can be decreased. Figure 10 shows a DC/DC converter in two-phase design. 


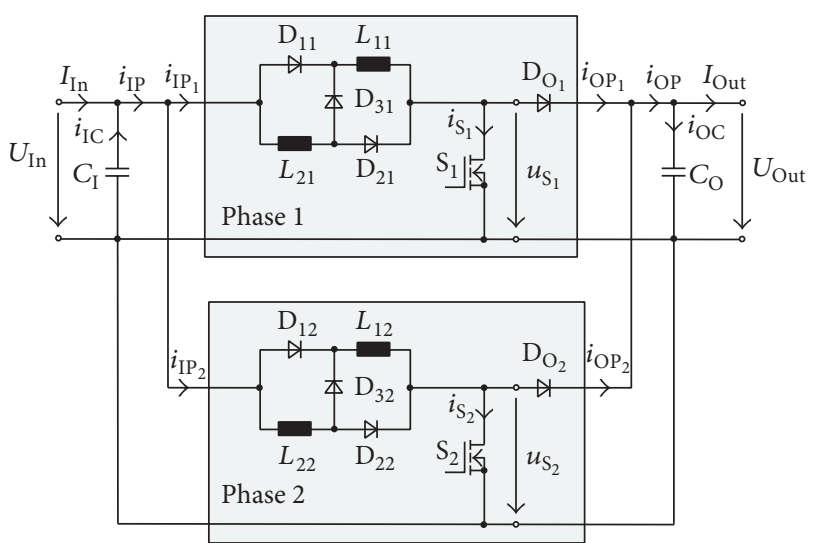

Figure 10: Two-phase hybrid boost DC/DC converter.
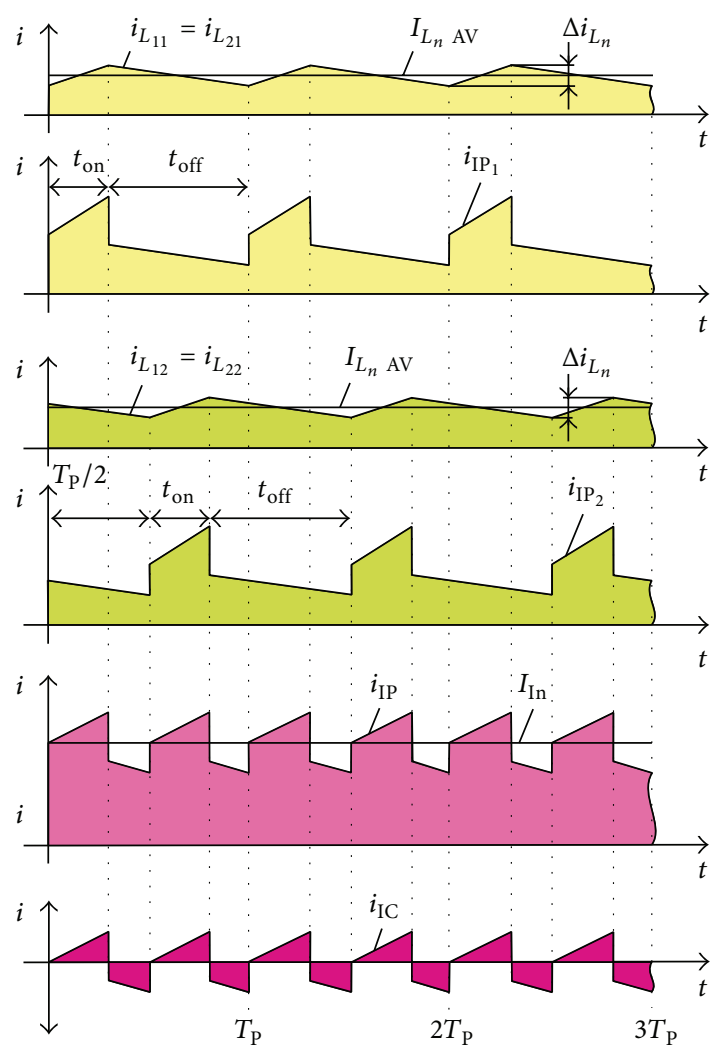

FIGURE 11: Current waveforms at the input of a two-phase hybrid boost DC/DC converter $(n=2, d=0.3)$.

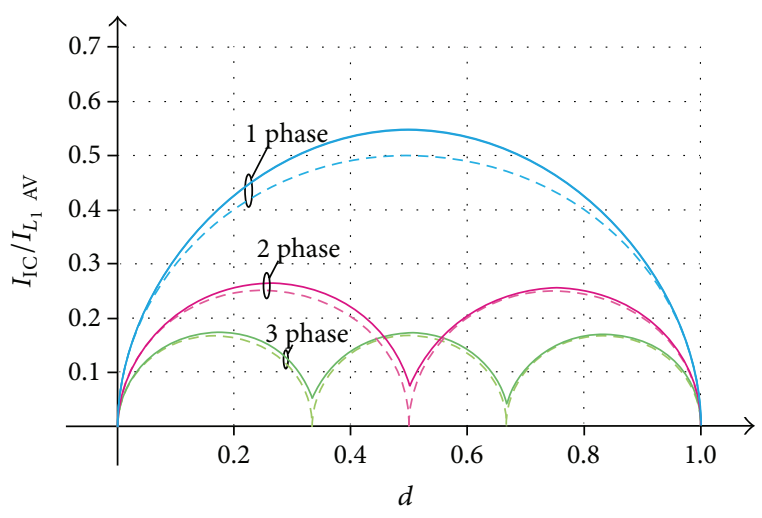

$\begin{aligned}-\Delta i_{L_{n} \max } & =0.5 \cdot I_{L_{n} \mathrm{AV}} \\ --\Delta i_{L_{n} \max } & =0\end{aligned}$

FIgURE 12: RMS current in the input capacitors of a one-, two-, and three-phase hybrid boost DC/DC converter.
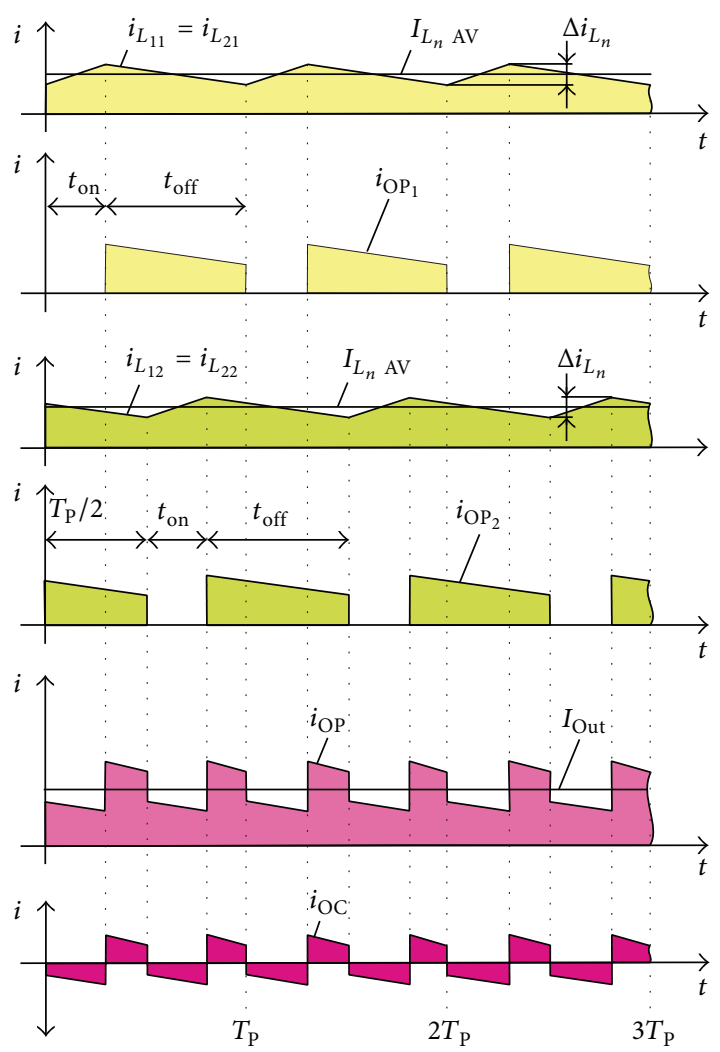

FIGURE 13: Current waveforms at the output of the two-phase hybrid boost DC/DC converter $(n=2, d=0.3)$. 
3.1. DC/DC Converter Input Circuit. In Figure 11 the current waveforms at the input of a two-phase hybrid boost converter are shown. First, the currents in both inductances and the input current of phase one are shown. Represented underneath in green are the same currents of phase two. The triangle shaped inductance currents of the two phases are shifted with about a half pulse period. At switched-on time the input current of each phase is twice as small as the inductance current from a single-phase converter. But in this circuit the overall input phase current $I_{\text {IP }}$ consists of the sum of all the input phase currents. The overall input phase current $I_{\text {IP }}$, with the DC-component $I_{\text {In }}$ is shown in Figure 11. Also for this circuit it is assumed that only the DC-current is flowing in the circuit input. With these conditions, for multiphase converters, the function between the input current $I_{\text {In }}$ and the average inductance current of the individual phases $I_{L_{n} \mathrm{AV}}$ can be calculated. Consider

$$
I_{L_{n} \mathrm{AV}}=\frac{I_{\mathrm{In}}}{n \cdot(1+d)} .
$$

The total AC-component of the overall input phase current $I_{\mathrm{IP}}$ flows in the input capacitor (Figure 11). This current is clearly smaller in comparison to a single-phase hybrid boost converter. In addition, the frequency of the capacitor current is doubled. For these reasons the filter effort is reduced.

We continue with the calculation of the inductances and capacitors of a multiphase hybrid boost converter. The same technical conditions for a single-phase converter are applied and the calculation of inductances for an $n$-phase design can be accomplished in the same way as for single-phase circuits. Taking into account the input current which is subdivided into the different phases, the maximum current variation in the inductances must be based on the maximum DCcurrent at rated power in the individual phases. For design, the maximum current variation is selected between $10 \%$ and $30 \%$ of the phase DC-current in the inductances at rated power. Consider

$$
\begin{gathered}
L_{1 n}=L_{2 n}=\frac{U_{\mathrm{Out}} \cdot T_{\mathrm{P}}}{\Delta i_{L_{n} \max }} \cdot(3-2 \cdot \sqrt{2}) \\
\text { with } \Delta i_{L_{n} \max }=(0.1-0.3) \cdot I_{L_{n} \mathrm{AV} R} .
\end{gathered}
$$

The amplitude of the triangle current variation in the inductors is dependent on the duty cycle of the converter. Because the duty cycle in all phases has the same value, the current variations in all inductors are equivalent. Consider

$$
\Delta i_{L_{n}}=\frac{(d) \cdot(1-d)}{(1+d) \cdot(3-2 \cdot \sqrt{2})} \cdot \Delta i_{L_{n} \max } .
$$

The necessary input capacity of the multiphase hybrid boost converter will now be calculated. Compared to a singlephase design, the capacitor current is reduced and the current frequency is increased by the number of phases. As a consequence the current in the capacitor has a voltage variation at the input. For the capacitor design, the permissible static voltage variation in general is selected smaller than $1 \%$ of the rated input voltage. Consider

$$
C_{\mathrm{I}}=\frac{T_{\mathrm{P}} \cdot I_{L_{n} \mathrm{AV}}}{4 \cdot n \cdot \Delta u_{\mathrm{In} \max }} \quad \text { with } \Delta u_{\mathrm{In} \max } \leq 0.01 \cdot u_{\mathrm{In} R}
$$

In these $\mathrm{DC} / \mathrm{DC}$ converters, electrolytic capacitors are used often. A main design criterion of these capacitors is the RMS current load. For this reason, for multiphase DC/DC converters the RMS current in the input capacitor $C_{\mathrm{I}}$ will be calculated. Therefore the switching processes in the phases are assumed as ideal. Moreover, it is accepted that the current in the input is an ideal DC-current. The worst case scenario will happen when the capacitor is loaded with the total ACcurrent component.

The input capacitor current for two-phase converters is represented in Figure 12. In the case of closer inspection the capacitor current can be split into two different components: a rectangle part and a triangle part. The RMS current of these two components has been calculated. The RMS result of the rectangle portion for multiphase converters is shown in the formula below:

$$
\begin{aligned}
& I_{\text {IC П }} \\
& \mid \begin{array}{rr}
\sqrt{I_{L_{n} \mathrm{AV}}^{2} \cdot n^{2} \cdot\left(d-\frac{0}{n}\right) \cdot\left(\frac{1}{n}-d\right)} & \text { if } \frac{0}{n} \leq d \\
& \leq \frac{1}{n} \\
\sqrt{I_{L_{n} \mathrm{AV}}^{2} \cdot n^{2} \cdot\left(d-\frac{1}{n}\right) \cdot\left(\frac{2}{n}-d\right)} & \text { if } \frac{1}{n} \leq d \\
\sqrt{I_{L_{n} \mathrm{AV}}^{2} \cdot n^{2} \cdot\left(d-\frac{2}{n}\right) \cdot\left(\frac{3}{n}-d\right)} & \text { if } \frac{2}{n} \leq d \\
& \leq \frac{2}{n} \\
\sqrt{I_{L_{n} \mathrm{AV}}^{2} \cdot n^{2} \cdot\left(d-\frac{n-1}{n}\right) \cdot\left(\frac{n}{n}-d\right)} & \text { if } \frac{n-1}{n} \leq d \\
& \leq \frac{n}{n}
\end{array} .
\end{aligned}
$$

In this formula it is necessary to consider that the average inductance current $I_{L_{n}}$ AV becomes smaller with an increasing number of phases. For example, the average inductance current $I_{L_{n} A V}$ in a two-phase converter is only half as big as in a single-phase converter. With this fact in mind the rectangle component of the input capacitor current can clearly be reduced with a multiphase design.

In addition, the RMS current of the triangle has been calculated. The next formula shows the RMS results for a multiphase circuit design. Consider 


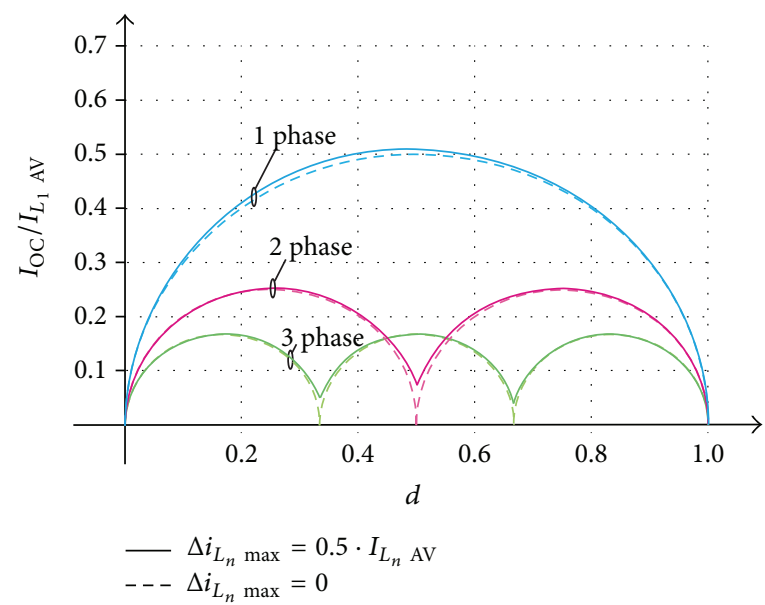

FIGURE 14: RMS current in the output capacitors of a one-, two-, and three-phase hybrid boost DC/DC converter.

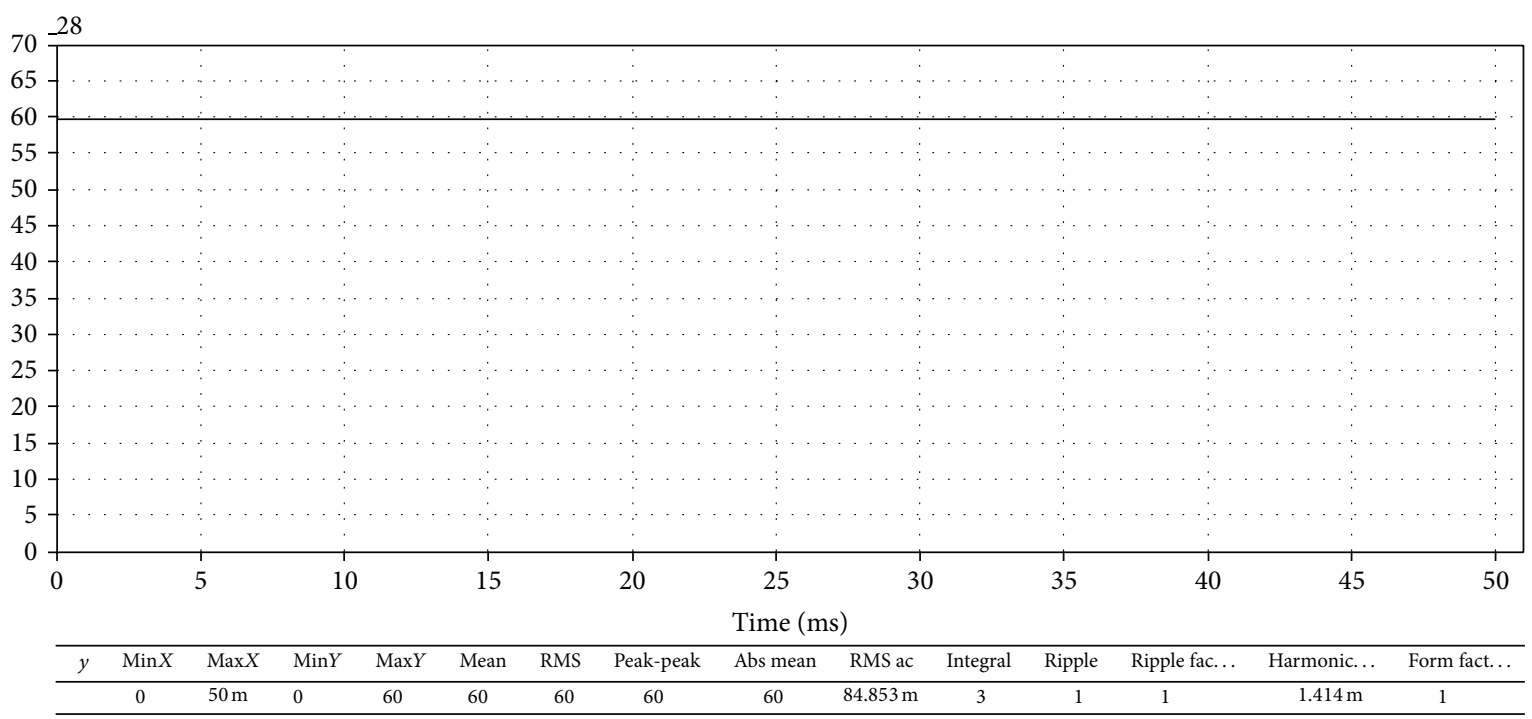

FIGURE 15: Input voltage.

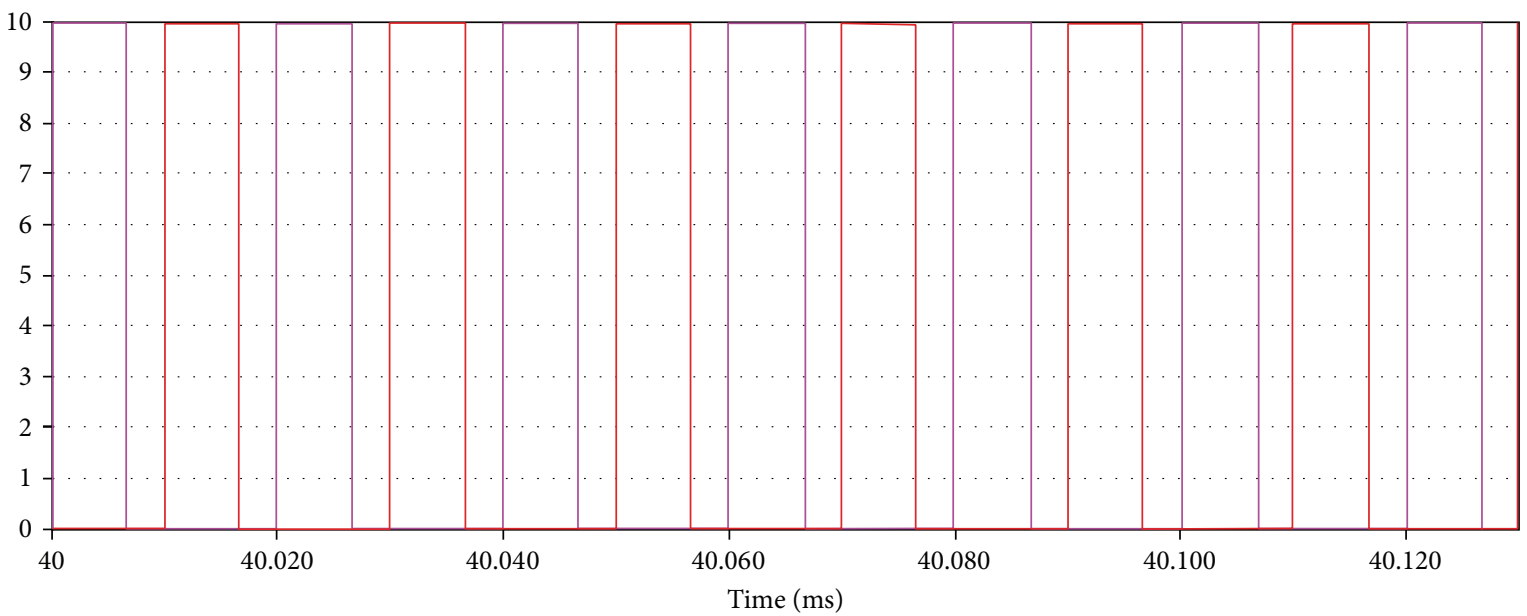

Signal $1-$ Signal 2

\begin{tabular}{cccccccccccccccc}
\hline$t$ & $y$ & $\operatorname{Min} X$ & $\operatorname{Max} X$ & $\operatorname{Min} Y$ & $\operatorname{Max} Y$ & Mean & RMS & Peak-peak & Abs mean & RMS ac & Integral & Ripple & Ripple fac... & Harmonic... & Form fact... \\
\hline $40.007 \mathrm{~m}$ & 10 & 0 & $50 \mathrm{~m}$ & 0 & 10 & 3.320 & 5.762 & 10 & 3.320 & 4.709 & $165.982 \mathrm{~m}$ & 1.736 & 3.012 & $817.335 \mathrm{~m}$ & 1.736 \\
$40.007 \mathrm{~m}$ & 0 & 0 & $50 \mathrm{~m}$ & 0 & 10 & 3.320 & 5.762 & 10 & 3.320 & 4.709 & $165.980 \mathrm{~m}$ & 1.736 & 3.012 & $817.335 \mathrm{~m}$ & 1.736 \\
\hline
\end{tabular}

FIGURE 16: PWM pulse applied to switch one (pink signal), respective switch two (red signal). 


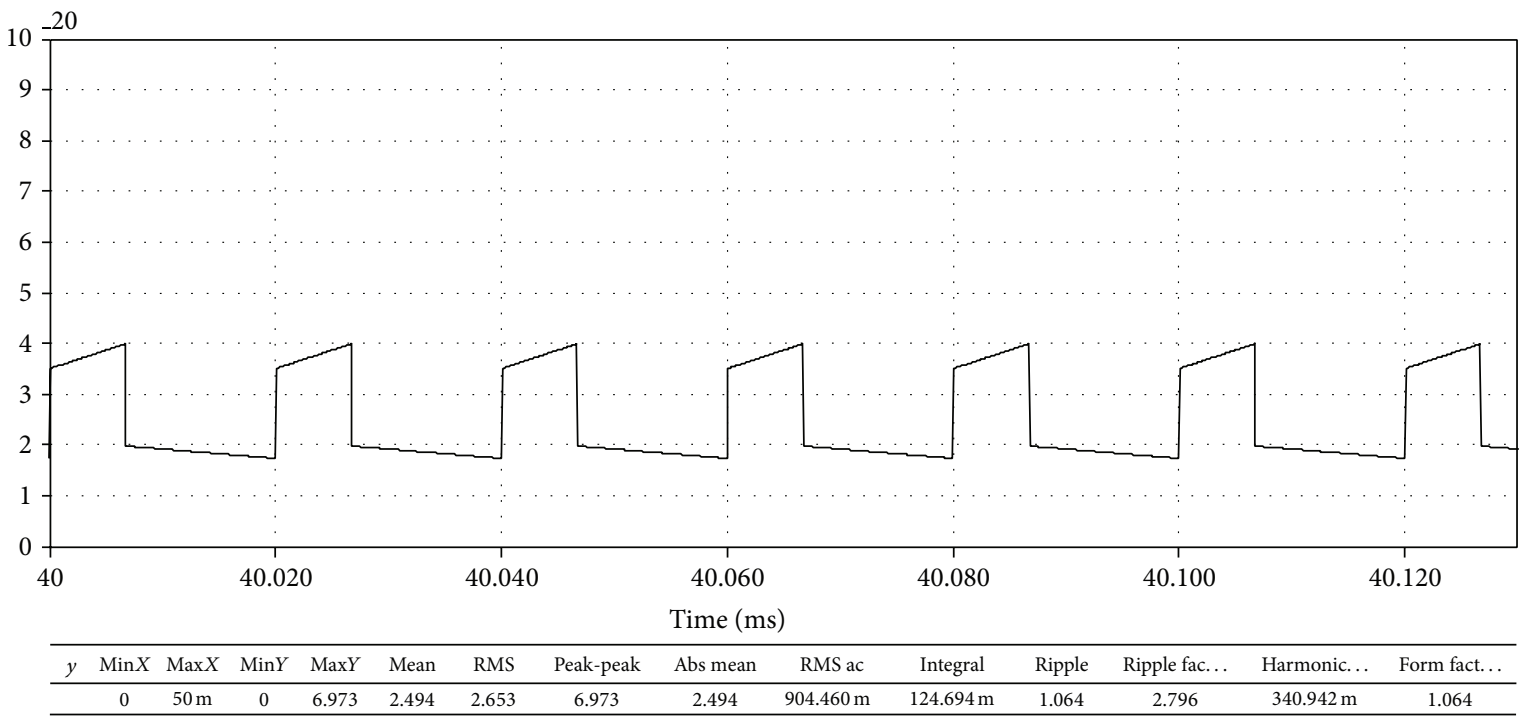

FIGURE 17: Input current of phase one, $i_{\mathrm{IP}_{1}}$.

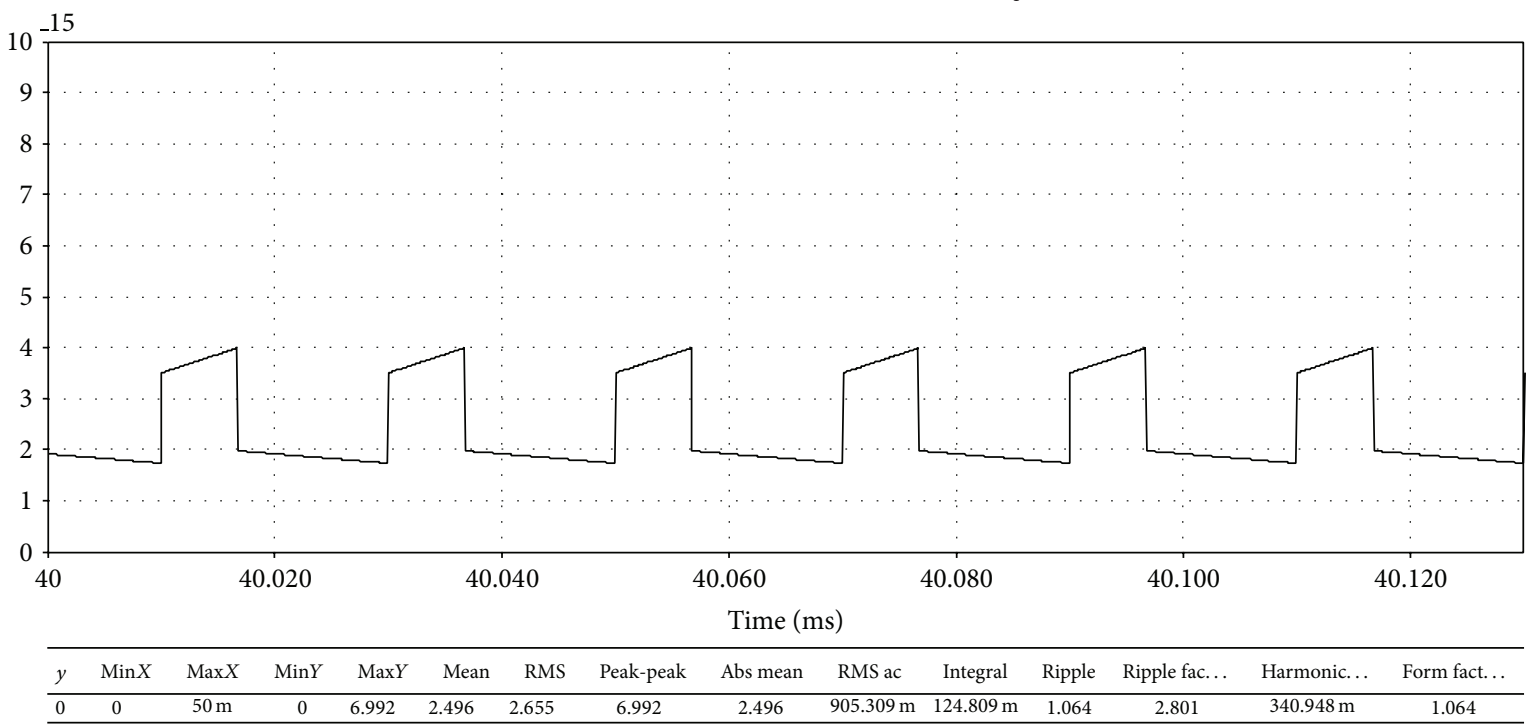

FIGURE 18: Input current of phase two, $i_{\mathrm{IP}_{2}}$.

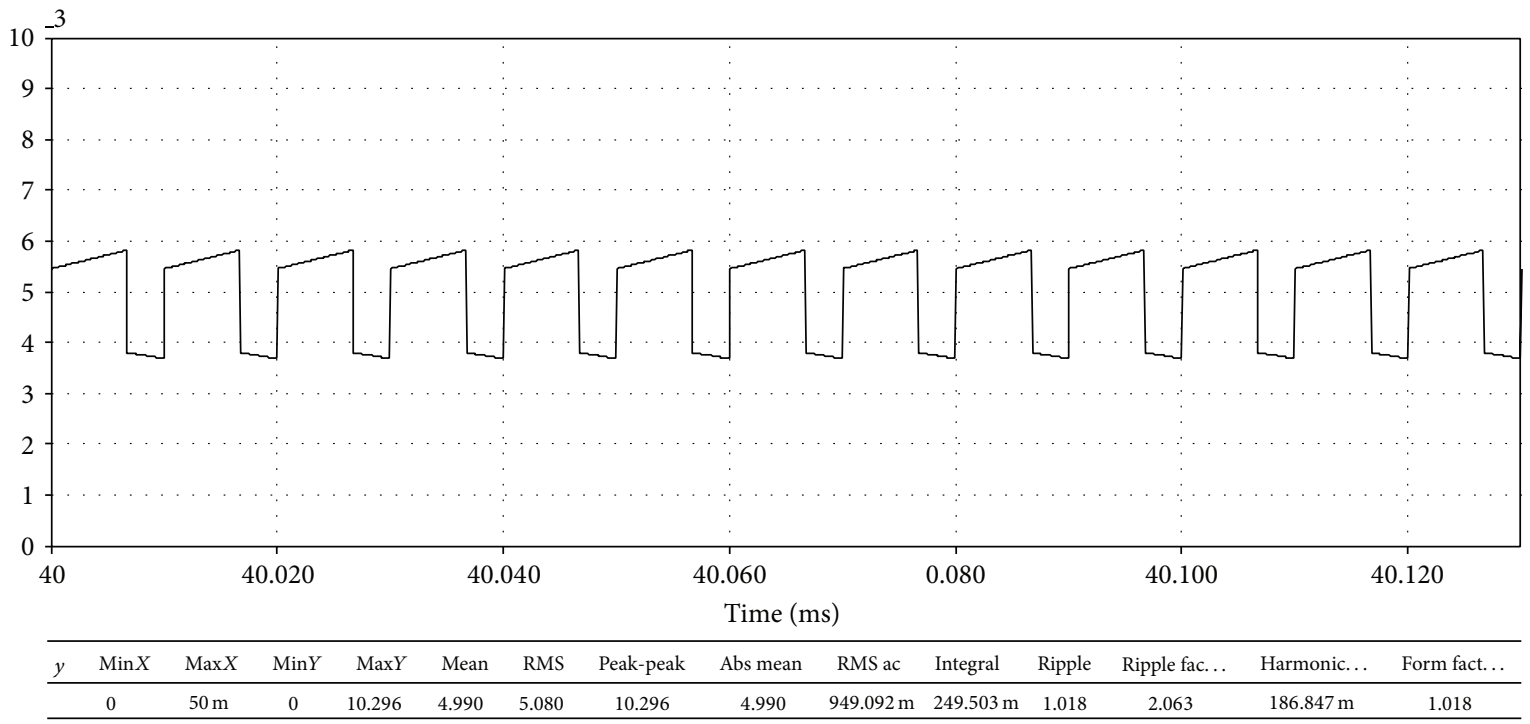

FIGURE 19: Overall input phase current, $i_{\mathrm{IP}}$. 


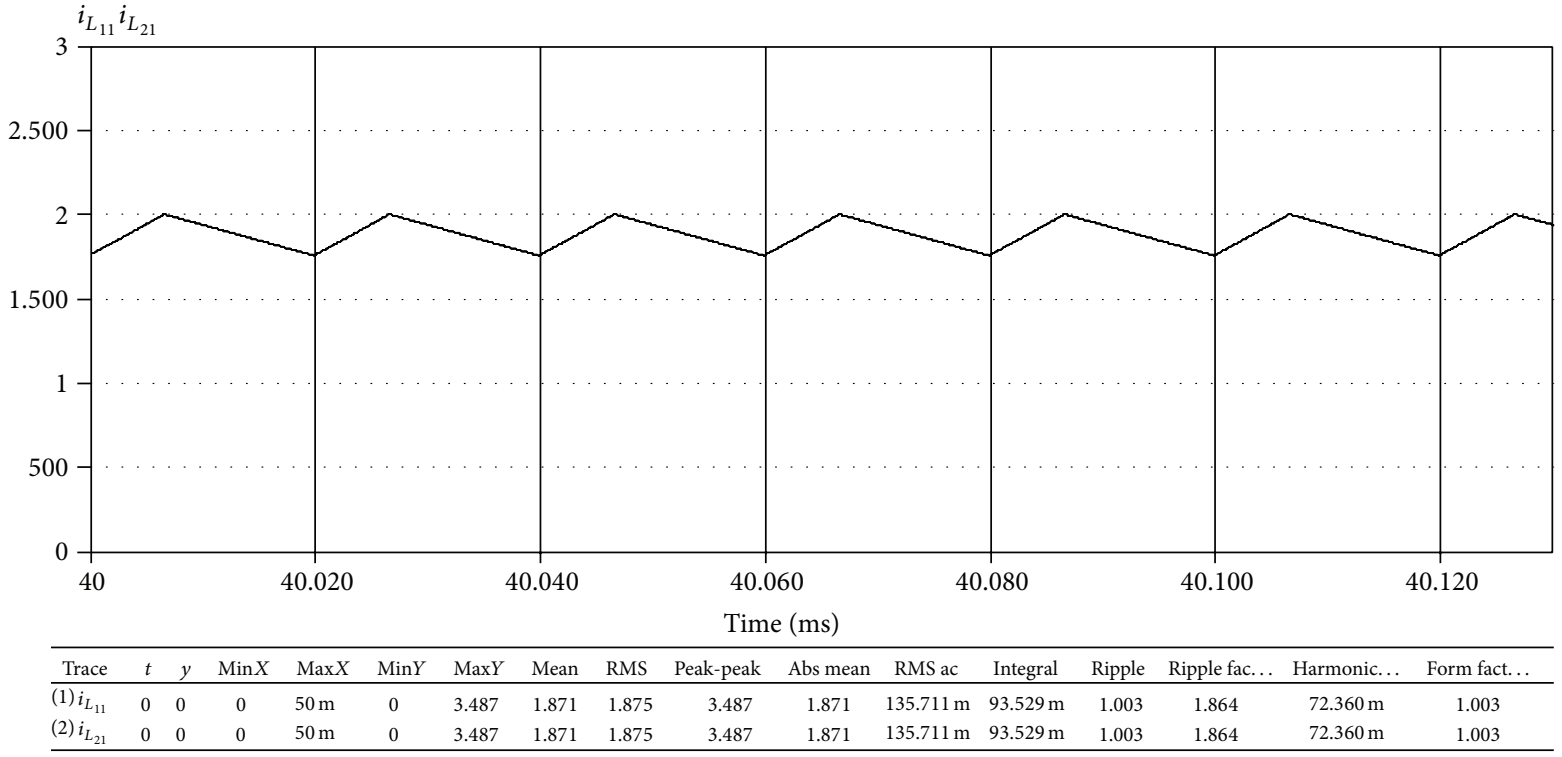

FIGURE 20: Current through inductors $L_{11}$ and $L_{21}, i_{L_{11}}, i_{L_{21}}$.

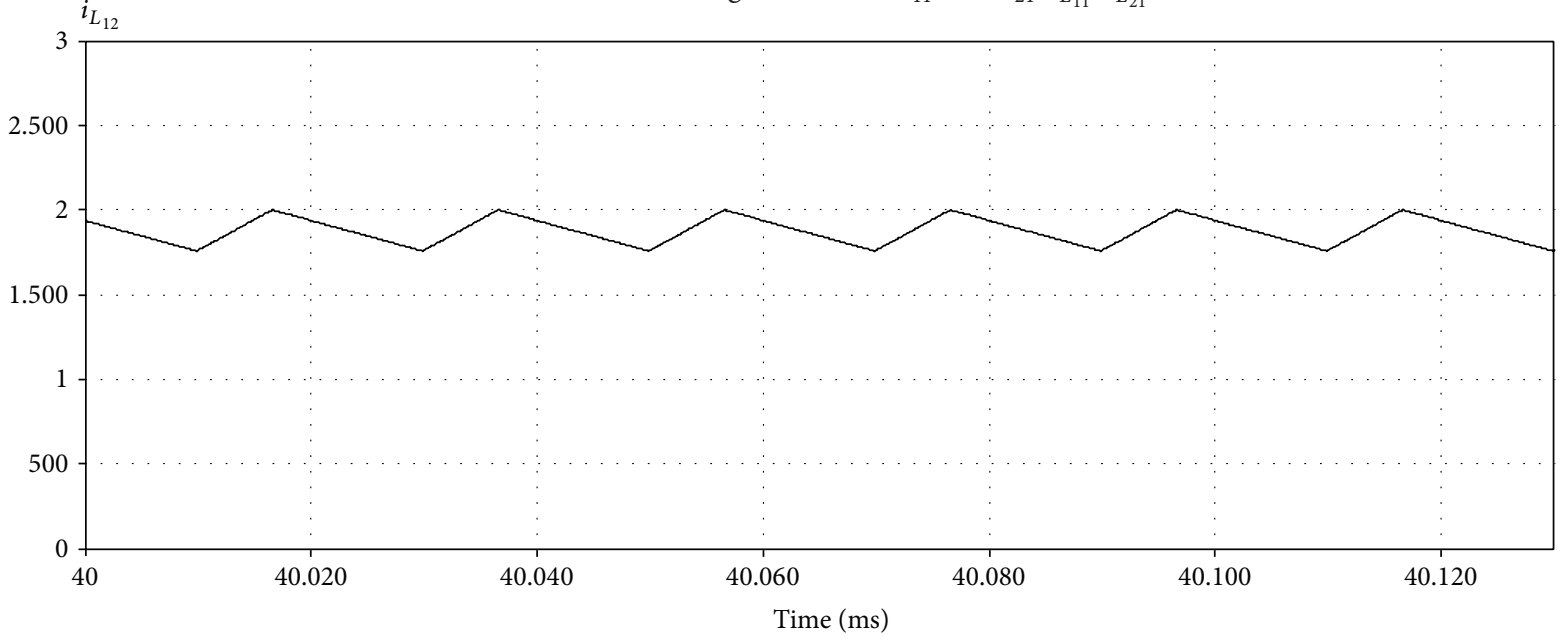

\begin{tabular}{|c|c|c|c|c|c|c|c|c|c|c|c|c|c|c|c|}
\hline$t$ & $y$ & $\operatorname{Min} X$ & $\operatorname{Max} X$ & $\operatorname{Min} Y$ & $\operatorname{Max} Y$ & Mean & RMS & Peak-peak & Abs mean & RMS ac & Integral & Ripple & Ripple fac... & Harmonic. . & Form fact... \\
\hline $40.024 \mathrm{~m}$ & 1.879 & 0 & $50 \mathrm{~m}$ & 0 & 3.496 & 1.872 & 1.877 & 3.496 & 1.872 & $135.792 \mathrm{~m}$ & $93.608 \mathrm{~m}$ & 1.003 & 1.867 & $72.343 \mathrm{~m}$ & 1.003 \\
\hline
\end{tabular}

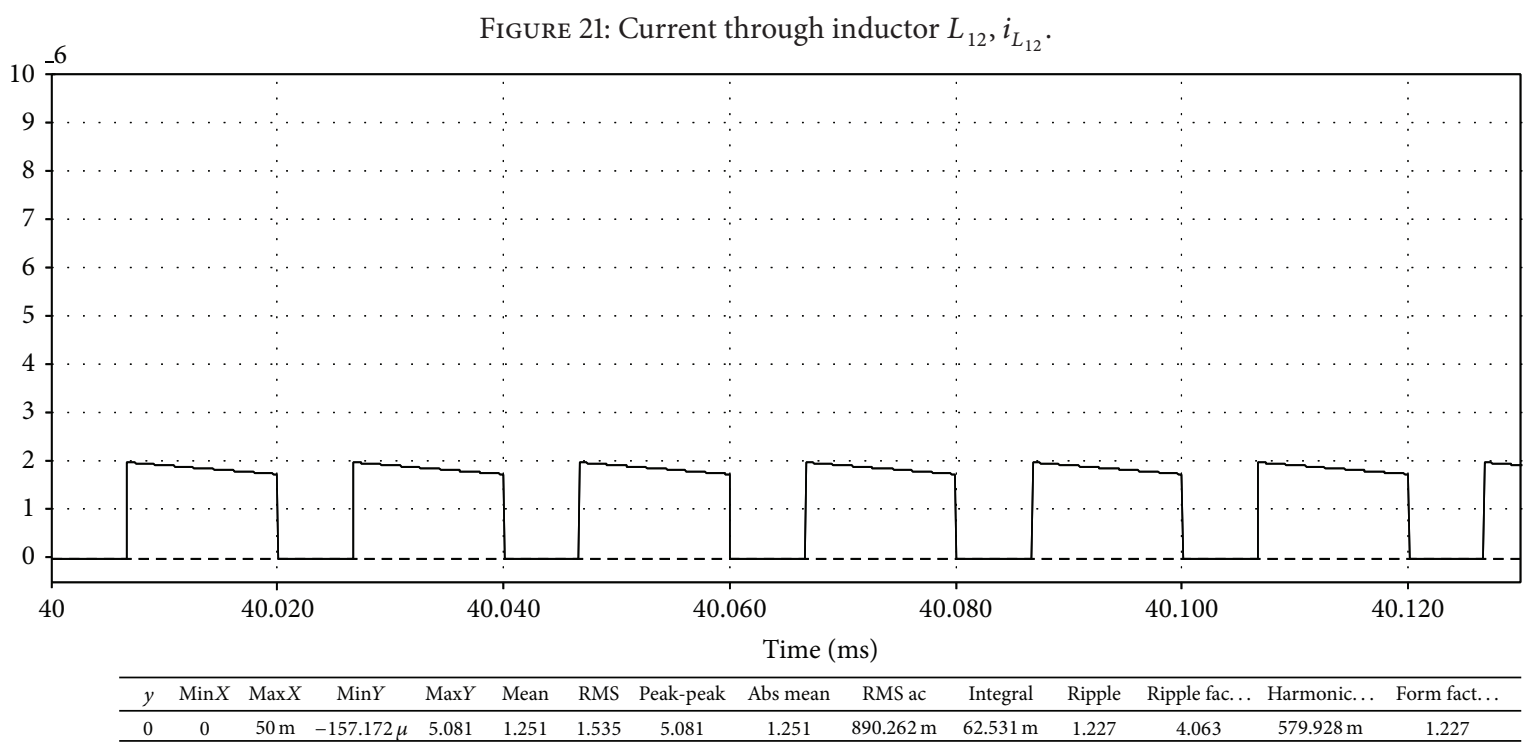

FIGURE 22: Output current of phase one, $i_{\mathrm{OP}_{1}}$. 


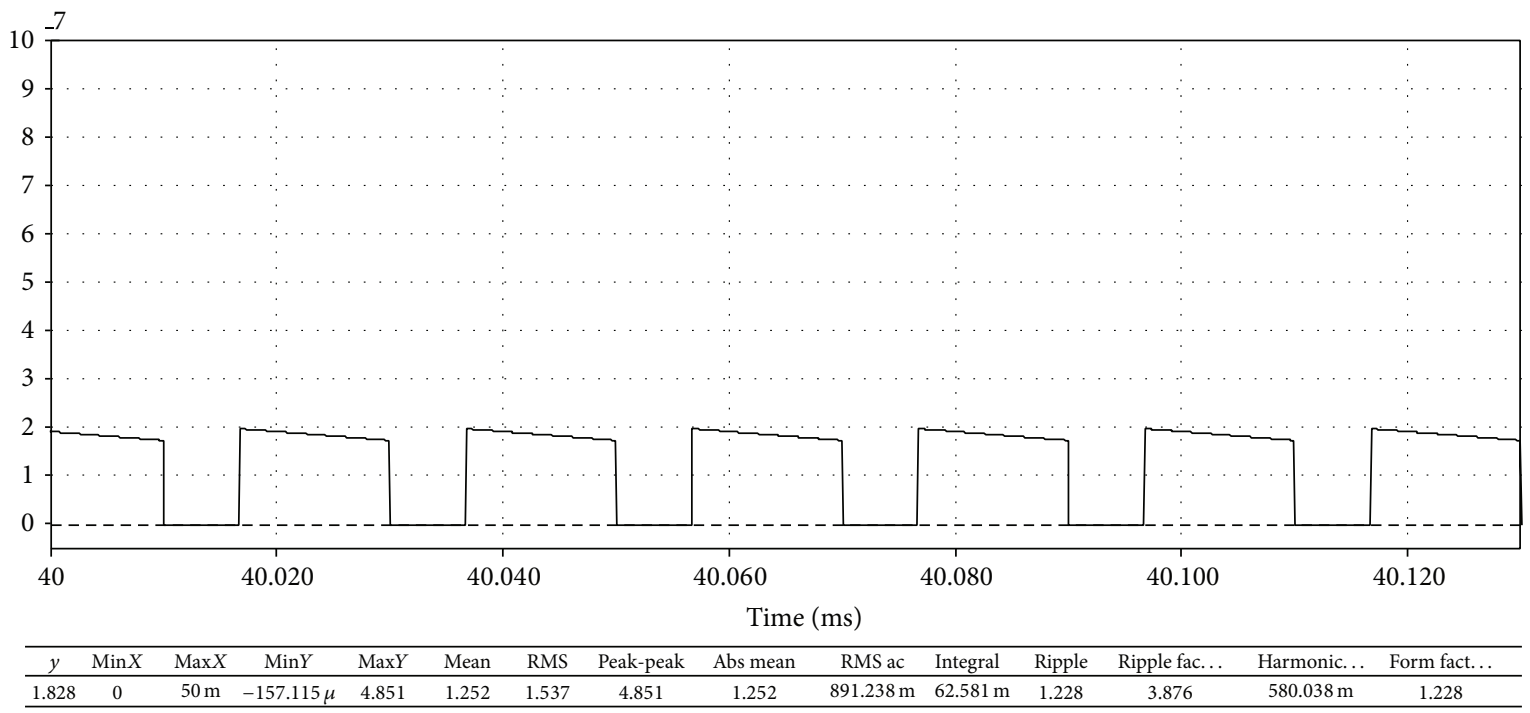

FIGURE 23: Output current of phase two, $i_{\mathrm{OP}_{2}}$.

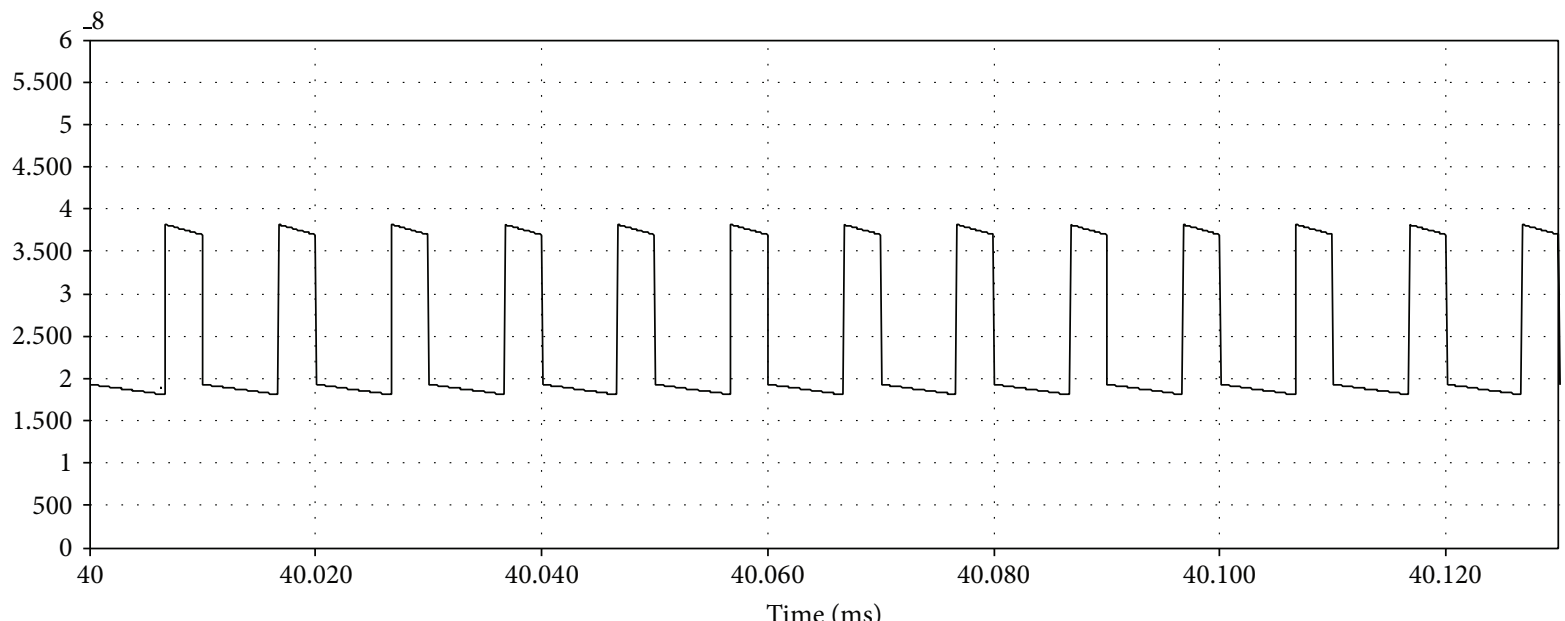

\begin{tabular}{cccccccccccc}
\hline$t$ & $y$ & $\operatorname{Min} X$ & $\operatorname{Max} X$ & $\operatorname{Min} Y$ & $\operatorname{Max} Y$ & Mean & RMS & Peak-peak & Abs mean & RMS ac & Integral \\
\hline
\end{tabular}

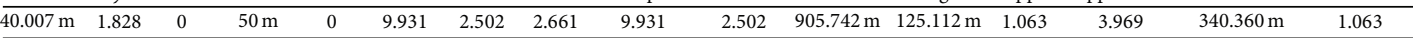

FIGURE 24: Overall output phase current, $i_{\mathrm{OP}}$.

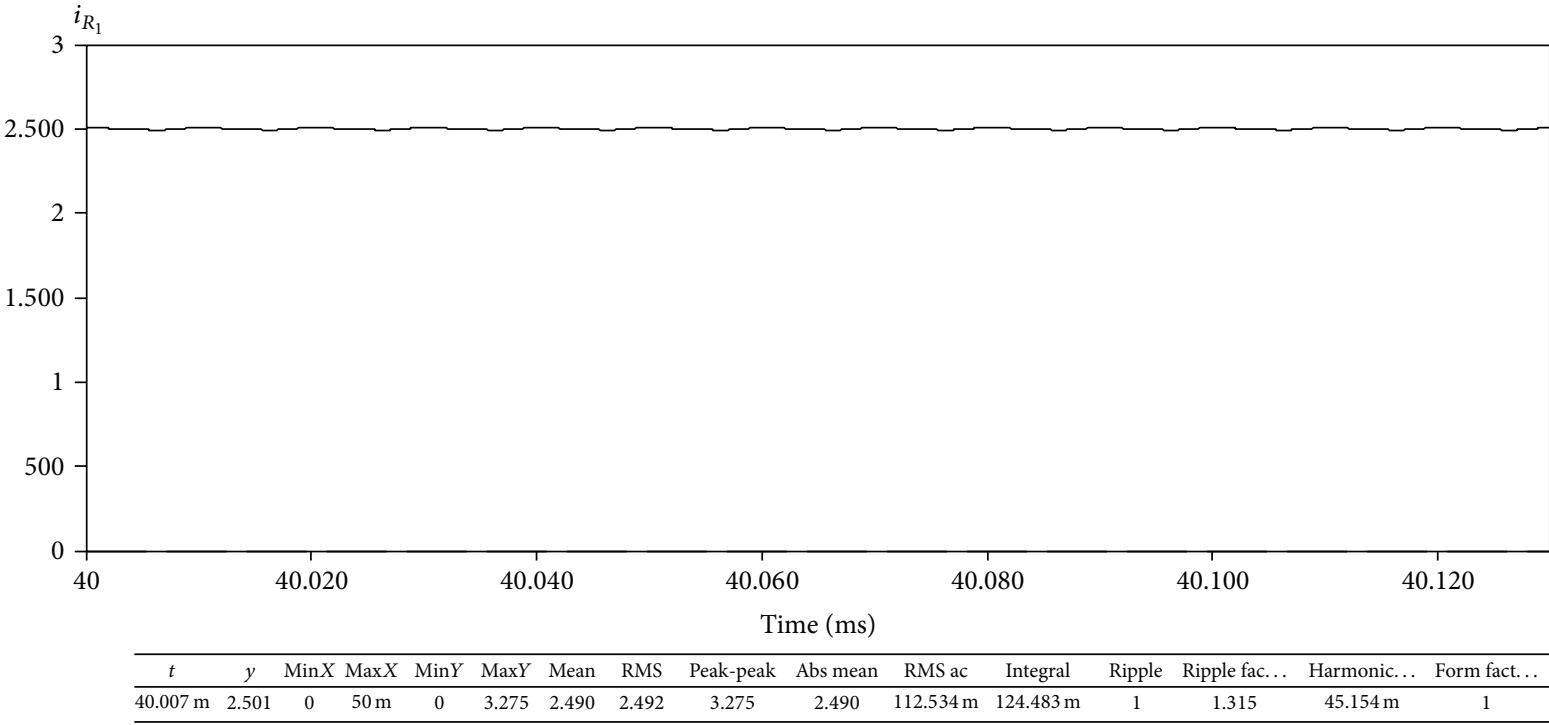

FIGURE 25: Output current, $I_{\text {Out }}$. 


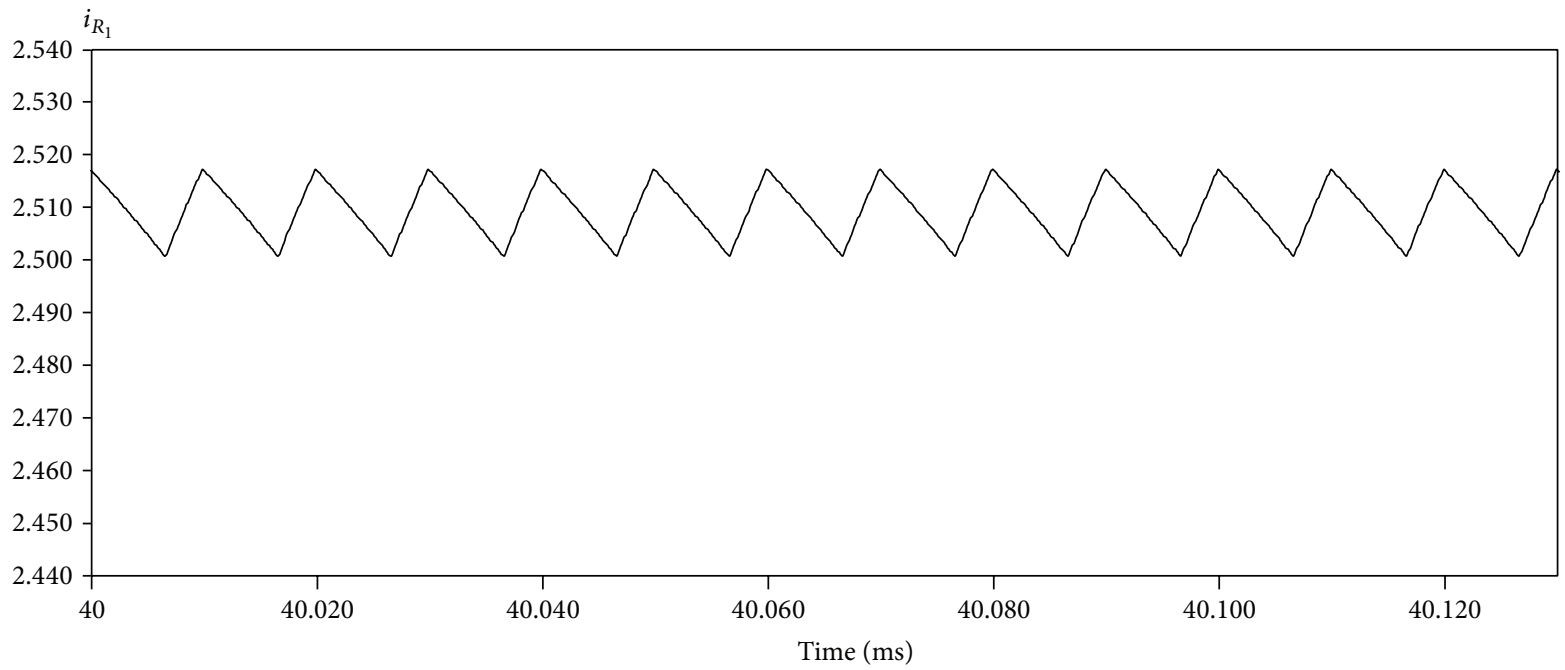

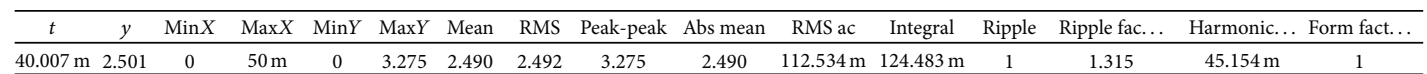

FIgURE 26: Zoom on output current.

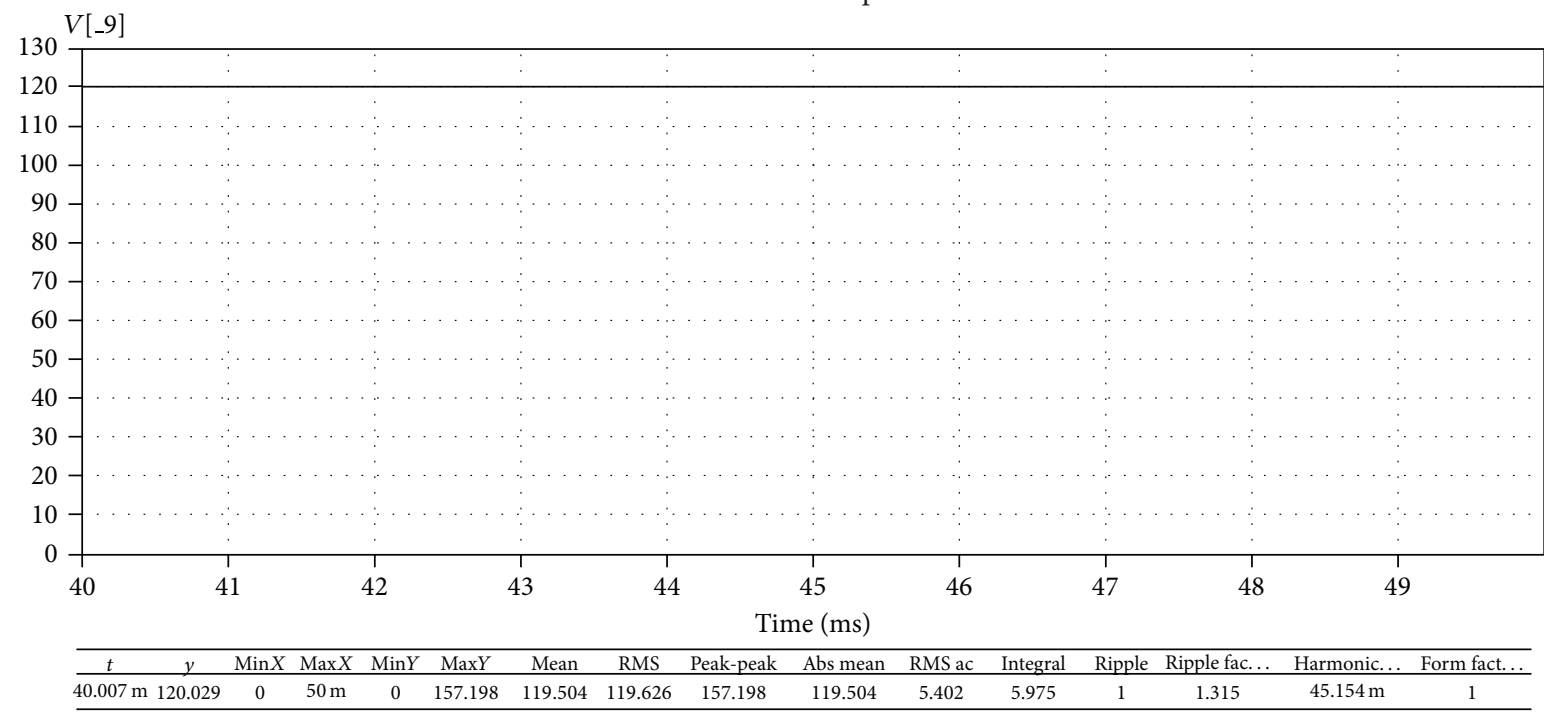

Figure 27: Output voltage, $V_{\text {Out }}$.

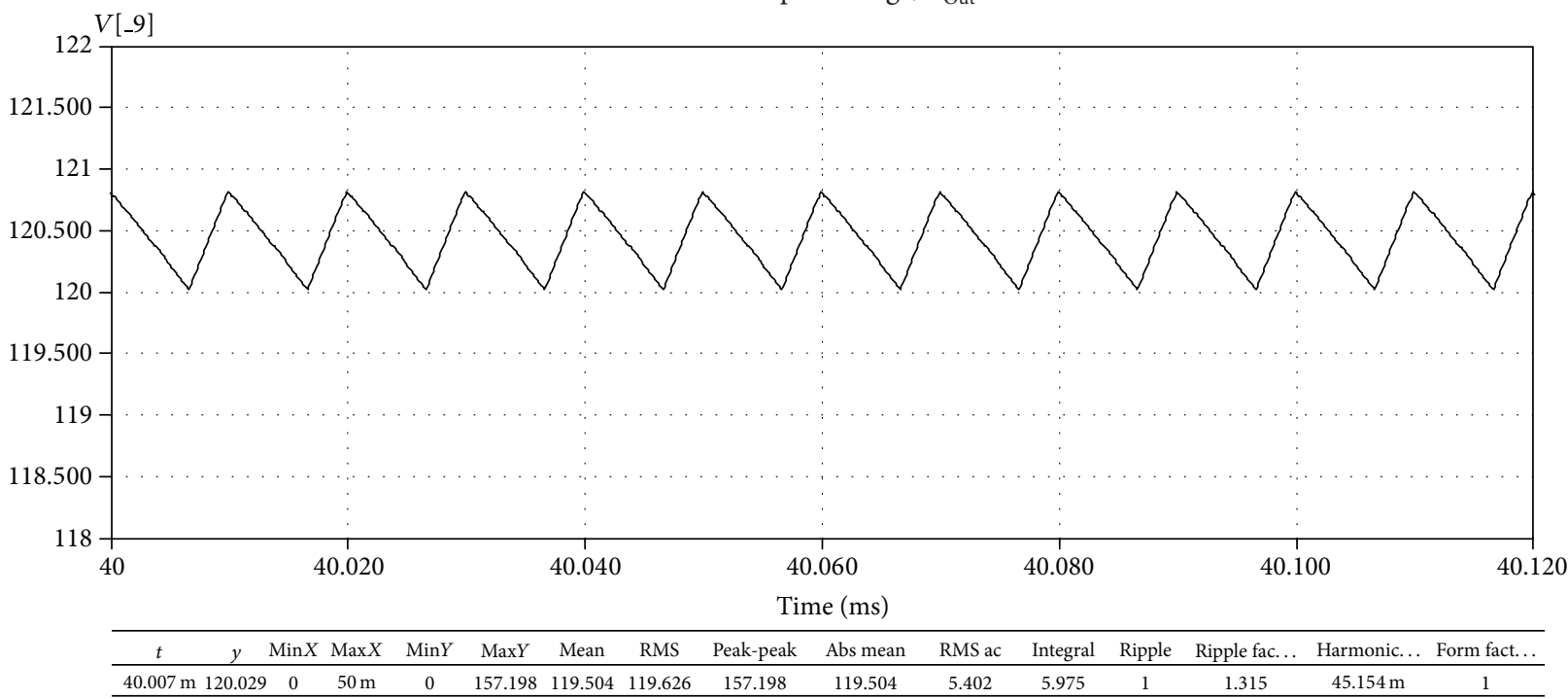

FIGURE 28: Zoom on output voltage, $V_{\text {Out }}$. 


$$
\begin{aligned}
& I_{\text {IC } \Delta}
\end{aligned}
$$

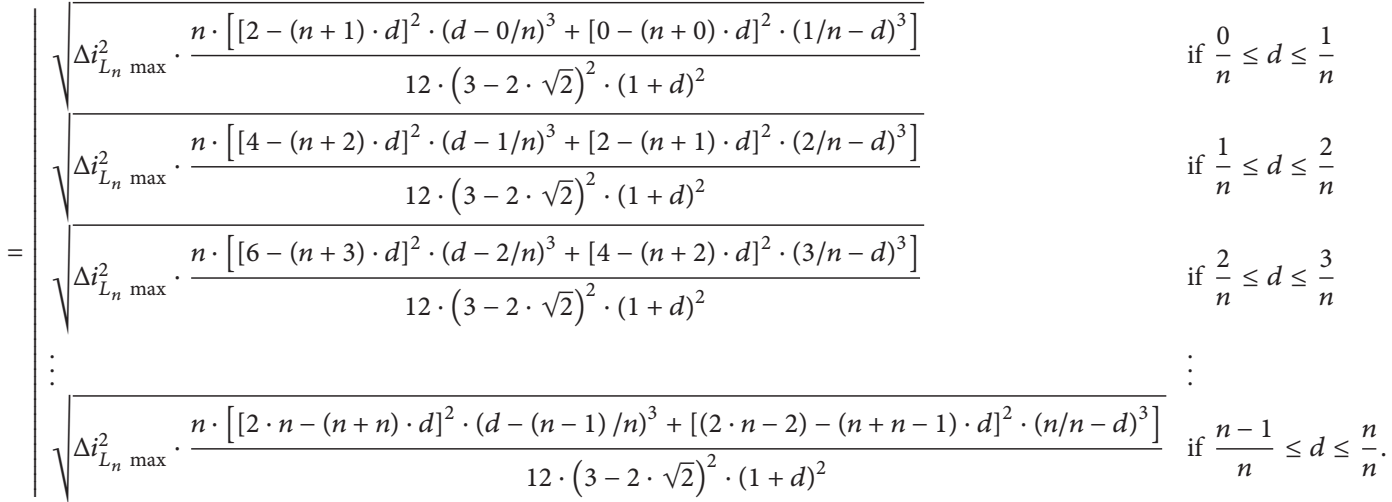

The current variation $\Delta i_{L_{n} \text { max }}$ in this formula is selected in relation to the rated average inductance current $I_{L_{n}} \mathrm{AV}$ during the circuit dimension. This will mean that with the same circuit dimension and increasing number of phases, the current variation is reduced.

The geometrical addition of rectangle and triangle RMS components results in the total capacitor current for an $n$ phase hybrid boost DC/DC converter. Consider

$$
I_{\mathrm{IC}}=\sqrt{I_{\mathrm{IC} \Pi}^{2}+I_{\mathrm{IC} \Delta}^{2}}
$$

Figure 12 shows the RMS current in the input capacitors of multiphase DC/DC converters. The current load of the capacitor decreases with the increasing number of phases. The influence of the rectangle RMS component is clearly dominant (dotted lines, $i_{L_{n} \max }=0$ ). The maximum capacitor current component produced from the rectangle portion is smaller by a factor of $1 / n$ for $n$-phase converters. The triangle capacitor current is not dependent on the converter power and has, for all loads, the same value. In case of rated power the additional load from the triangle current in the capacitors is small.

3.2. DC/DC Converter Output Circuit. Figure 13 shows the current waveforms at the output of a two-phase hybrid boost DC/DC converter. First, the currents in both inductors and the output current of phase 1 are represented. In the middle the current of phase 2 is shown. The triangle inductance current of the two phases is shifted within about a half pulse period of each other. At switched-off times, the inductors are connected in series and the current flows to the output phase, just as in a single-phase converter. However, in this circuit, the overall output phase current $I_{\mathrm{OP}}$ consists of the sum of all the output phase currents. The overall output phase current $I_{\mathrm{OP}}$ with the DC-component $I_{\mathrm{Out}}$ is shown Figure 13. It is assumed that only the DC-current is flowing in the circuit output; the total AC-component of the overall output phase current $I_{\mathrm{OP}}$ flows in the output capacitor. In comparison to a single-phase hybrid boost converter this current is clearly smaller. In addition, the frequency of the capacitor current has been doubled.

The necessary output capacity of the multiphase hybrid boost converter will next be calculated. Compared to a single-phase design, the output capacitor current is reduced and the current frequency is increased by the number of phases. As a consequence the current in the capacitor has a voltage variation at the output. For the capacitor design the permissible static voltage variation in general is selected at less than $1 \%$ of the rated output voltage. Consider

$$
C_{\mathrm{O}}=\frac{T_{\mathrm{P}} \cdot I_{L_{n} \mathrm{AV}}}{4 \cdot n \cdot \Delta u_{\text {Out } \max }} \quad \text { with } \Delta u_{\text {Out } \max } \leq 0.01 \cdot u_{\text {Out } R} .
$$

The RMS current in the output capacitor $C_{\mathrm{O}}$ will next be calculated for multiphase hybrid boost DC/DC converters. The output capacitor current for a two-phase converter is represented in Figure 13. Like the input capacitor, the output capacitor current can also be split into a rectangle and a triangle component. The RMS current of the rectangle portion for multiphase converters is shown in the formula below:

$I_{\mathrm{OC} \Pi}$

$$
=\mid \begin{array}{cc}
\sqrt{I_{L_{n} \mathrm{AV}}^{2} \cdot n^{2} \cdot\left(d-\frac{0}{n}\right) \cdot\left(\frac{1}{n}-d\right)} & \text { if } \frac{0}{n} \leq d \leq \frac{1}{n} \\
\sqrt{I_{L_{n} \mathrm{AV}}^{2} \cdot n^{2} \cdot\left(d-\frac{1}{n}\right) \cdot\left(\frac{2}{n}-d\right)} & \text { if } \frac{1}{n} \leq d \leq \frac{2}{n} \\
\sqrt{I_{L_{n} \mathrm{AV}}^{2} \cdot n^{2} \cdot\left(d-\frac{2}{n}\right) \cdot\left(\frac{3}{n}-d\right)} & \text { if } \frac{2}{n} \leq d \leq \frac{3}{n} \\
\vdots & \vdots \\
\sqrt{I_{L_{n} \mathrm{AV}}^{2} \cdot n^{2} \cdot\left(d-\frac{n-1}{n}\right) \cdot\left(\frac{n}{n}-d\right)} & \text { if } \frac{n-1}{n} \leq d \leq \frac{n}{n}
\end{array}
$$

The output capacitor RMS current, that is, produced by the rectangle component is exactly the same as that in 
the input capacitor. It is necessary to also consider that the average inductance current $I_{L_{n} \mathrm{AV}}$ becomes smaller with the increasing number of phases. The next formula shows the output capacitor RMS component produced by the triangle part of multiphase converters. Consider

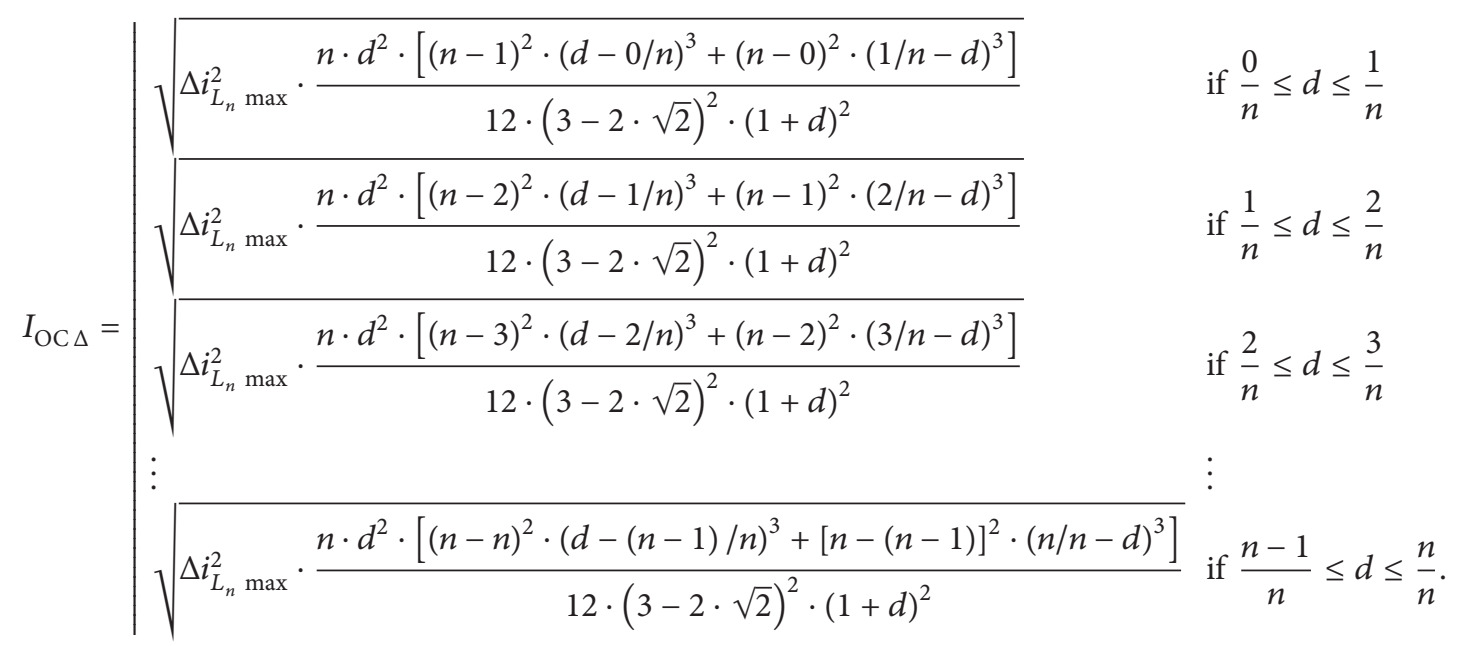

The geometrical addition of rectangle and triangle RMS components results in the total capacitor current for $n$-phase converters. Consider

$$
I_{\mathrm{OC}}=\sqrt{I_{\mathrm{OC} \Pi}^{2}+I_{\mathrm{OC} \Delta}^{2}}
$$

In Figure 14 the RMS current in the output capacitors of multiphase DC/DC converters is shown. The current load of the capacitor decreases with the increasing number of phases. If neglecting the current variation $\left(\Delta i_{L_{n} \max }=0\right.$, dotted lines), the maximum current in the output capacitor $C_{\mathrm{O}}$ is smaller for $n$-phase converters by a factor of $1 / n$ compared to a single-phase design. The load in the output capacitors produced by the triangle current is fixed by the inductance converter design. This capacitor current is not dependent on the converted power. If the converter is operated with rated output power, this current has only a small influence on the overall capacitor current. In the figure, the output capacitor current is represented with a current variation of $\Delta i_{L_{n} \mathrm{~N} \text { max }}=$ $0.5 I_{L_{n} \mathrm{AV}}$. The influence of the triangle current at the output capacitors is smaller than at the input side of the converter.

The calculations indicate that the triangle current load in the input and output capacitor for multiphase converters is clearly reduced. Putting this knowledge into practice, the triangle current in the inductances can be selected more largely $[42,43]$. The dynamics of the hybrid boost DC/DC converter can be improved and beyond that the inductance and capacitor effort of the circuit can be reduced substantially.

Besides the calculated current in the capacitors also is flowing harmonics current produced by switching processes of the phases [44]. This current has been examined in [45-47] for different converters. In consequence, these results can also be used for a hybrid boost converter. The additional current can contribute substantially to the output capacitors, heating up the capacitors during the small load of the converter. However, with higher power the calculated capacitor current dominates. A statement for all semiconductor types cannot be made. Beyond that, this additional current is dependent on the pulse frequency of the converter.

3.3. Simulation of the Two-Phase Hybrid Boost DC/DC Converter. We made this simulation of the two-phase hybrid boost DC/DC converter in CASPOC simulation program with a power source, not with a PV module. The following parameters are used for simulation: $P_{\text {In }}=300 \mathrm{~W}, U_{\text {In }}=60 \mathrm{~V}$, $I_{\text {In }}=5 \mathrm{~A}, L_{11}=L_{21}=L_{12}=L_{22}=823.55 \mu \mathrm{H}, C_{\mathrm{I}}=$ $15.625 \mu \mathrm{F}, C_{\mathrm{O}}=5.208 \mu \mathrm{F}$, and $f_{s}=50 \mathrm{kHz}$.

In previous Figures 15, 16, 17, 18, 19, 20, 21, 22, 23, 24, $25,26,27$, and 28 are presented the results of simulation. Figure 16 presents the PWM pulses applied to switch 1, corresponding to first phase of the converter, respective the PWM pulses applied to switch 2, corresponding to the second phase of the converter. Figure 17 show the input current of phase 1, Figure 18 show the input current of phase 2, and the overall input phase current which consists of the sum of all the input phase currents, in our case phase one and phase two it is presented in Figure 19. It is obvious from Figure 20 that the currents of phase one through inductors $L_{11}$ and $L_{21}\left(i_{L_{11}}\right.$, $\left.i_{L_{21}}\right)$ are equal. The currents of phase two through inductors $L_{12}$ and $L_{22}\left(i_{L_{12}}, i_{L_{22}}\right)$ are equal, but here is represented just one of them in Figure 21. Output current of phase 1, respective 2 , and the overall output phase current which consists of the sum of all the output phase currents, in our case phase one and phase two, are presented in Figures 22, 23, and 24. In the last figures are presented the output current and voltage, and the ripple of them.

\section{Conclusion}

Beginning from a step-up hybrid boost converter which was introduced in [22], after analyses this circuit and seeing if it 
is suitable for a PV system, we realize that one of the main disadvantages of this circuit is that the effort for the input and output capacitor, in the case of a single-phase DC/DC converter, is very high. This is the same with the effort of the inductors. A method for reducing this disadvantage was based on the same structure of the hybrid boost converter but built in a multiphase design. To ensure that all the phases of the converter operate at the same switching frequency and with phase-shift between them, we used interleaving switching strategy. After we analyze this new multiphase hybrid boost converter, made the theoretical calculation, and sketch the waveform, our presumption became true. The effort of the inductors, of the input and output capacitor, is decreased and at the same time their size is reduced. The frequency of the capacitor currents is increased with the number of phase. To validate and confirm our theoretical calculation, we simulate this circuit in CASPOC [48] simulation program.

Therefore, how it is obvious from theoretical calculation and waveforms associated to it, compared with the simulation waveforms, we can see a very good accordance. Based on this, next step will be to put this circuit into practice.

\section{Conflict of Interests}

The authors declare that there is no conflict of interests regarding the publication of this paper.

\section{Acknowledgments}

This work was partially supported by the strategic Grant POSDRU 107/1.5/S/77265, inside POSDRU Romania 20072013 cofinanced by the European Social Fund-Investing in People.

\section{References}

[1] A. Campoccia, L. Dusonchet, E. Telaretti, and G. Zizzo, "Comparative analysis of different supporting measures for the production of electrical energy by solar PV and Wind systems: four representative European cases," Solar Energy, vol. 83, no. 3, pp. 287-297, 2009.

[2] T. Andrejašič, M. Jankovec, and M. Topič, "Comparison of direct maximum power point tracking algorithms using en 50530 dynamic test procedure," IET Renewable Power Generation, vol. 5, no. 4, pp. 281-286, 2011.

[3] S. S. W. Walker, N. K. Sooriyaarachchi, N. D. B. Liyanage, P. A. G. S. Abeynayake, and S. G. Abeyratne, "Comparative analysis of speed of convergence of MPPT techniques," in Proceedings of the 2011 6th International Conference on Industrial and Information Systems (ICIIS '11), pp. 522-526, Kandy, Sri Lanka, August 2011.

[4] M. Liserre, T. Sauter, and J. Y. Hung, "Future energy systems: integrating renewable energy sources into the smart power grid through industrial electronics," IEEE Industrial Electronics Magazine, vol. 4, no. 1, pp. 18-37, 2010.

[5] J. M. Carrasco, L. G. Franquelo, J. T. Bialasiewicz et al., "Powerelectronic systems for the grid integration of renewable energy sources: a survey," IEEE Transactions on Industrial Electronics, vol. 53, no. 4, pp. 1002-1016, 2006.

[6] A. Das, V. K. Rajput, A. Chakraborty, M. Dhar, S. Ray, and R. Dutta, "A new transformerless DC-DC converter with high voltage gain," in Proceedings of the 2010 International Conference on Industrial Electronics, Control and Robotics (IECR '10), pp. 9194, December 2010.

[7] O. Abdel-Rahim, M. Orabi, E. Abdelkarim, M. Ahmed, and M. Z. Youssef, "Switched inductor boost converter for PV applications," in Proceedings of the 27th Annual IEEE Applied Power Electronics Conference and Exposition (APEC '12), pp. 2100-2106, February 2012.

[8] R. J. Wai, C. Y. Lin, R. Y. Duan, and Y. R. Chang, "Highefficiency dc-dc converter with high voltage gain and reduced switch stress," IEEE Transactions on Industrial Electronics, vol. 54, no. 1, pp. 354-364, 2007.

[9] B. R. Lin and F. Y. Hsieh, "Soft-switching zeta-flyback converter with a buck-boost type of active clamp," IEEE Transactions on Industrial Electronics, vol. 54, no. 5, pp. 2813-2822, 2007.

[10] K. C. Tseng and T. J. Liang, "Novel high-efficiency step-up converter," IEE Proceedings: Electric Power Applications, vol. 151, no. 2, pp. 182-190, 2004.

[11] T. F. Wu, Y. S. Lai, J. C. Hung, and Y. M. Chen, "Boost converter with coupled inductors and buck-boost type of active clamp," IEEE Transactions on Industrial Electronics, vol. 55, no. 1, pp. $154-162,2008$.

[12] W. Li, X. Lv, Y. Deng, J. Liu, and X. He, "A review of nonisolated high step-up DC/DC converters in renewable energy applications," in Proceedings of the 24th Annual IEEE Applied Power Electronics Conference and Exposition (APEC '09), pp. 364-369, IEEE, February 2009.

[13] A. Tomaszuk and A. Krupa, "High efficiency high step-up DC/DC converters-a review," Bulletin of the Polish Academy of Sciences: Technical Sciences, vol. 59, no. 4, pp. 475-483, 2011.

[14] R. J. Wai, W. H. Wang, and C. Y. Lin, "High-performance standalone photovoltaic generation system," IEEE Transactions on Industrial Electronics, vol. 55, no. 1, pp. 240-250, 2008.

[15] V. M. E. Thirumurugan and S. B. E. Sugumar, "High-efficiency step-up converter by using PV system with reduced diode stresses sharing," International Journal of Engineering and Advanced Technology, vol. 4, no. 2, pp. 319-324, 2014.

[16] Y. P. Hsieh, J. F. Chen, T. J. Liang, and L. S. Yang, "Novel high step-up dc-dc converter for distributed generation system," IEEE Transactions on Industrial Electronics, vol. 60, no. 4, pp. 1473-1482, 2013.

[17] S. M. Chen, T. J. Liang, L. S. Yang, and J. F. Chen, "A safety enhanced, high step-up DC-DC converter for AC photovoltaic module application," IEEE Transactions on Power Electronics, vol. 27, no. 4, pp. 1809-1817, 2012.

[18] S. Y. Tseng and H. Y. Wang, "A photovoltaic power system using a high step-up converter for DC load applications," Energies, vol. 6, no. 2, pp. 1068-1100, 2013.

[19] S. M. Chen, T. J. Liang, L. S. Yang, and J. F. Chen, "A cascaded high step-up DC-DC converter with single switch for microsource applications," IEEE Transactions on Power Electronics, vol. 26, no. 4, pp. 1146-1153, 2011.

[20] Y. P. Hsieh, J. F. Chen, T. J. Liang, and L. S. Yang, "A novel high step-up DC-DC converter for a microgrid system," IEEE Transactions on Power Electronics, vol. 26, no. 4, pp. 1127-1136, 2011.

[21] K. Varuna and S. Kumar, "Modeling \& simulation of grid connected photovoltaic system using high step up DC/DC converter," International Journal of Latest Advances in Electronic and Electric Engineering, vol. 2, no. 2, pp. 153-158, 2013. 
[22] B. Axelrod, Y. Berkovich, and A. Ioinovici, "Switchedcapacitor/switched-inductor structures for getting transformerless hybrid DC-DC PWM converters," IEEE Transactions on Circuits and Systems I: Regular Papers, vol. 55, no. 2, pp. 687-696, 2008.

[23] L. Huber and M. M. Jovanovic, "Design approach for server power supplies for networking applications," in Proceedings of the 15th Annual IEEE Applied Power Electronics Conference and Exposition (APEC '00), pp. 1163-1169, February 2000.

[24] F. Renken and V. Karrer, "DC/DC converters for automotive board-net structures," in Proceedings of the International Power Electronics and Motion Control Conference (EPE-PEMC '04), Riga, Latvia, September 2004.

[25] F. Renken, "High temperature electronics for future hybrid drive systems," in Proceedings of the 13th European Conference on Power Electronics and Applications (EPE '09), pp. 1-7, Barcelona, Spain, September 2009.

[26] L. Huber and M. M. Jovanovic, "Design approach for server power supplies for networking applications," in Proceedings of the 15th Annual IEEE Applied Power Electronics Conference and Exposition (APEC '00), pp. 1163-1169, New Orleans, La, USA, February 2000.

[27] K. P. Yalamanchili, M. Ferdowsi, and K. Corzine, "New double input DC-DC converters for automotive applications," in Proceedings of the 2006 IEEE Vehicle Power and Propulsion Conference (VPPC '06), Windsor, UK, September 2006.

[28] M. Gavriş, O. Cornea, and N. Muntean, "Multiple input DCDC topologies in renewable energy systems-a general review," in Proceedings of the 3rd IEEE International Symposium on Exploitation of Renewable Energy Sources (EXPRES '11), pp. 123128, Subotica, Serbia, March 2011.

[29] M. J. V. Vázquez, J. M. A. Márquez, and F. S. Manzano, “A methodology for optimizing stand-alone PV-system size using parallel-connected DC/DC converters," IEEE Transactions on Industrial Electronics, vol. 55, no. 7, pp. 2664-2673, 2008.

[30] T. Hosi, "Control circuit for parallel operation of selfcommutating inverters," Japanese Patent S56-13101, 1975.

[31] R. Gules, J. D. P. Pacheco, H. L. Hey, and J. Imhoff, "A maximum power point tracking system with parallel connection for PV stand-alone applications," IEEE Transactions on Industrial Electronics, vol. 55, no. 7, pp. 2674-2683, 2008.

[32] S. V. G. Oliveira and I. Barbi, "A three-phase step-up DC-DC converter with a three-phase high frequency transformer," in Proceedings of the IEEE International Symposium on Industrial Electronics 2005 (ISIE '05), vol. 2, pp. 571-576, June 2005.

[33] P. Thounthong and B. Davat, "Study of a multiphase interleaved step-up converter for fuel cell high power applications," Energy Conversion and Management, vol. 51, no. 4, pp. 826-832, 2010.

[34] G. Y. Choe, J. S. Kim, H. S. Kang, and B. K. Lee, "An optimal design methodology of an interleaved boost converter for fuel cell applications," Journal of Electrical Engineering and Technology, vol. 5, no. 2, pp. 319-328, 2010.

[35] H. B. Shin, J. G. Park, S. K. Chung, H. W. Lee, and T. A. Lipo, "Generalised steady-state analysis of multiphase interleaved boost converter with coupled inductors," IEE Proceedings: Electric Power Applications, vol. 152, no. 3, pp. 584-594, 2005.

[36] T. Soepraptob, S. Sidopeksoc, and M. Taufik, "A Comparison of multiple boost configurations for small renewable energy battery storage systems," in Proceedings of the International Conference on Sustainable Energy Engineering and Application, pp. 93-96, Yogyakarta, Indonesia, 2012.
[37] W. Xiao, B. Zhang, and D. Qiu, "Analysis and design of an automatic-current-sharing control based on average-current mode for parallel boost converters," in Proceedings of the CES/IEEE 5th International Power Electronics and Motion Control Conference (IPEMC '06), pp. 1293-1297, August 2006.

[38] T. Taufik, R. Prasetyo, D. Dolan, and D. Garinto, "A new multiphase multi-interleaving buck converter with bypass LC," in Proceedings of the 36th Annual Conference of the IEEE Industrial Electronics Society (IECON '10), pp. 291-295, Phoenix, Ariz, USA, November 2010.

[39] Z. Lukí, S. M. Ahsanuzzaman, A. Prodí, and Z. Zhao, "Selftuning sensorless digital current-mode controller with accurate current sharing for multi-phase DC-DC converters," in Proceedings of the 24th Annual IEEE Applied Power Electronics Conference and Exposition (APEC '09), pp. 264-268, Washington, DC, USA, February 2009.

[40] P. L. Wong, P. Xu, B. Yang, and F. C. Lee, "Performance improvements of interleaving VRMs with coupling inductors," IEEE Transactions on Power Electronics, vol. 16, no. 4, pp. 499507, 2001.

[41] T. Taufik, T. Gunawan, D. Dolan, and M. Anwari, "Design and analysis of two-phase boost DC-DC converter," in World Academy of Science, Engineering and Technology, pp. 912-916, 2010.

[42] F. Renken, V. Karrer, and P. Skotzek P, "The starter generatorsystems, functions and components," in Proceedings of the 30th FISITA World Automotive Congress, Barcelona, Spain, May 2004.

[43] V. Karrer and F. Renken, "Power electronics for the integrated starter generator," in Proceedings of the Optimization of the Power Train in Vehicles by Using the Integrated Starter Generator (ISG '02), pp. 222-247, Haus der Technik e. V., Munich, Germany, 2002.

[44] F. Renken, "Analytic calculation of the DC-link capacitor current for pulsed single-phase H-bridge inverters," European Power Electronics and Drives Journal, vol. 13, no. 4, pp. 13-19, 2003.

[45] F. Renken, "Analytic calculation of the DC-link capacitor current for pulsed single-phase H-bridge inverters," European Power Electronics and Drives Journal, vol. 13, no. 4, pp. 13-19, 2003.

[46] F. Renken, "Analyses of the DC-link current in discontinuous modulated three-phase inverters," in Proceedings of the 12th International Power Electronics and Motion Control Conference (EPE-PEMC '06), Portorož, Slovenia, August-September 2006.

[47] F. Renken, "DC-link current in pulsed H-bridge inverters," in Proceedings of the International Exhibition \& Conference for Power Electronics, Intelligent Motion and Power Quality (PCIM '09), Nürnberg, Germany, May 2009.

[48] “CASPOC Simulation program," http://www.caspoc.com/. 

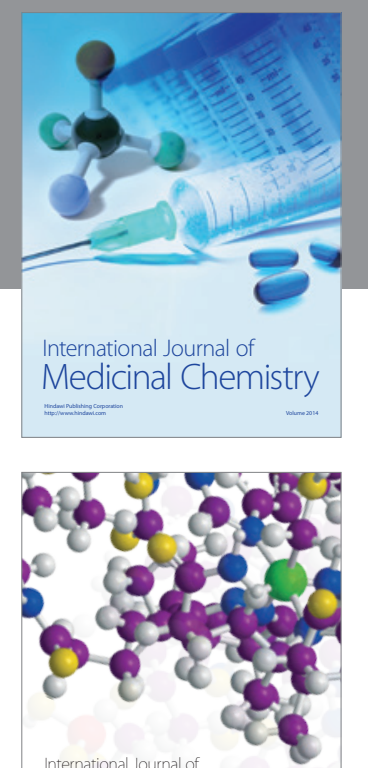

\section{Carbohydrate} Chemistry

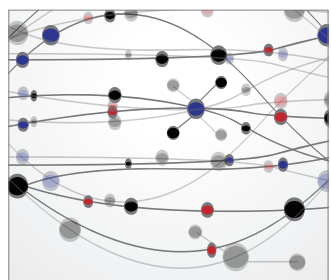

The Scientific World Journal
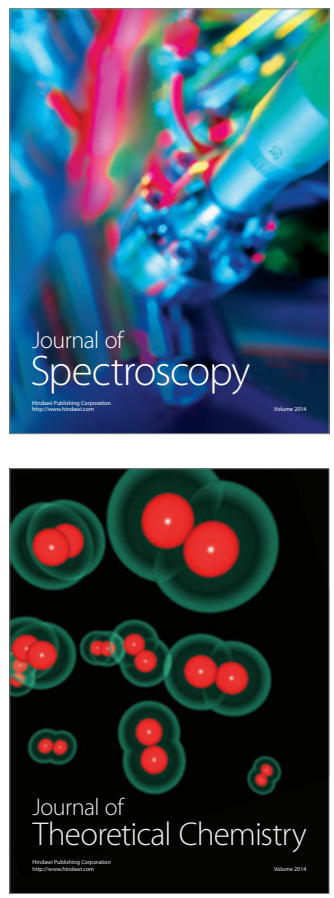
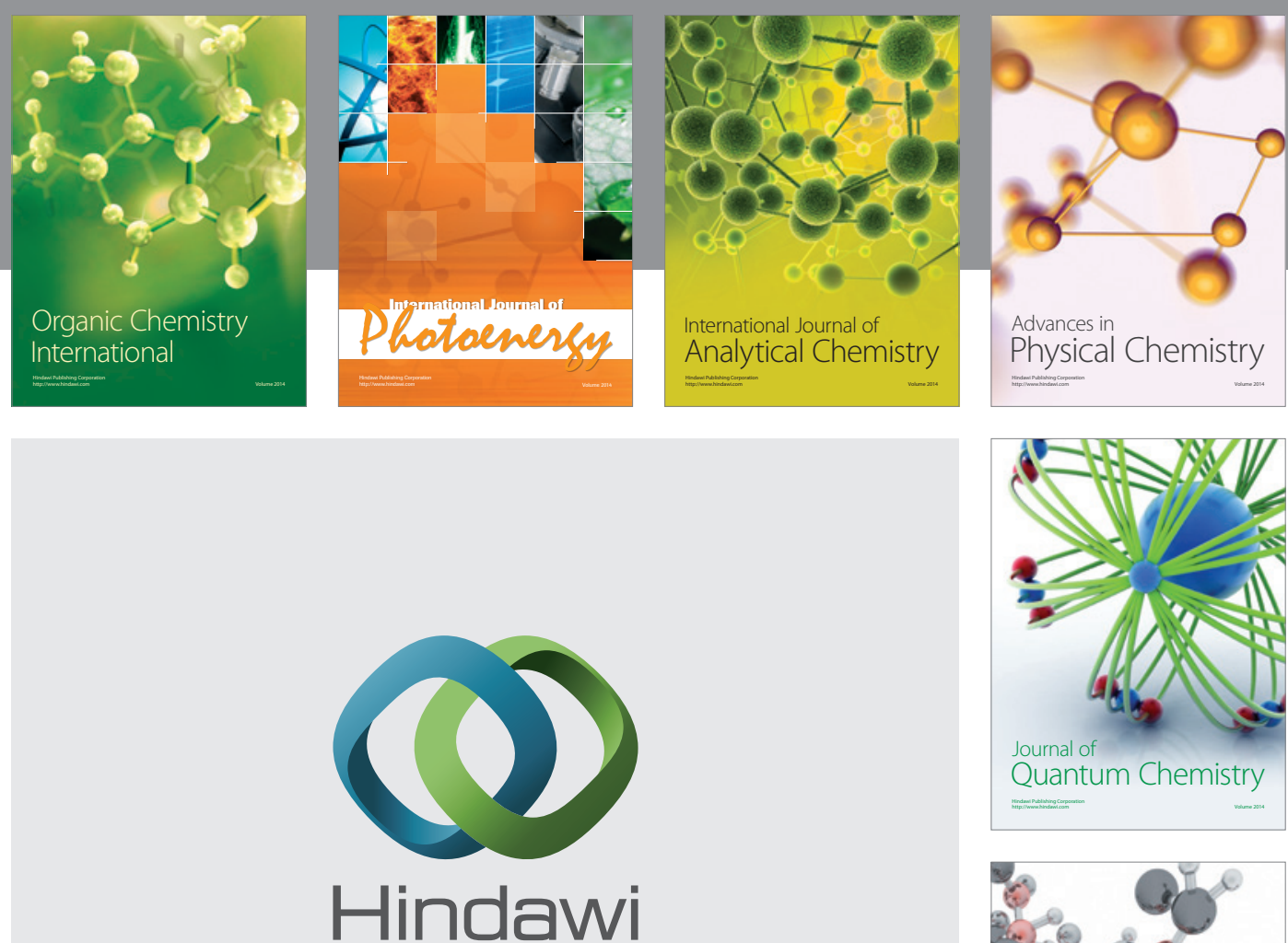

Submit your manuscripts at

http://www.hindawi.com

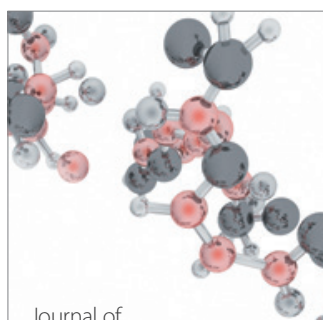

Analytical Methods

in Chemistry

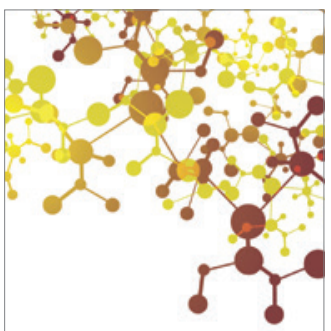

Journal of

Applied Chemistry

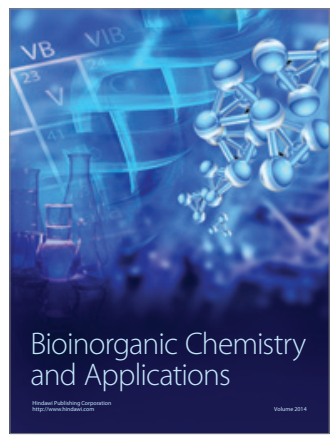

Inorganic Chemistry
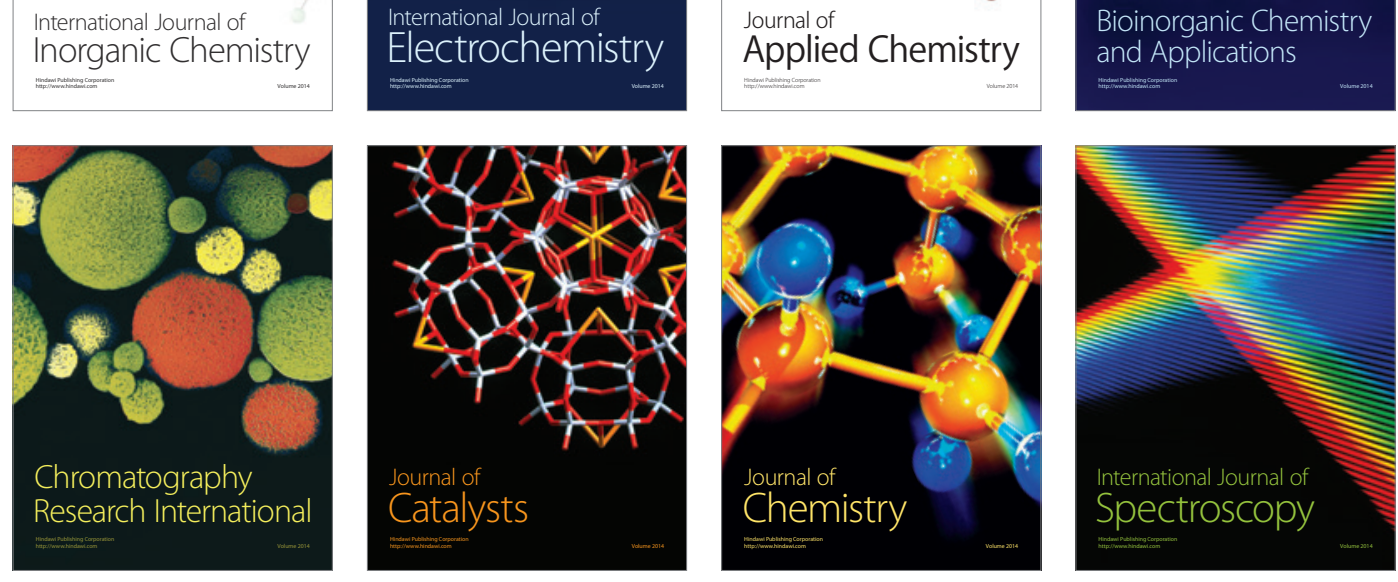